\title{
The multifaceted roles of perlecan in fibrosis
}

Megan S. Lord ${ }^{1}$, Fengying Tang ${ }^{1}$, Jelena Rnjak-Kovacina ${ }^{1}$, James G.W. Smith², James Melrose ${ }^{1,3,4}$, John M. Whitelock ${ }^{1}$,

${ }^{1}$ Graduate School of Biomedical Engineering, UNSW Sydney, NSW 2052, Australia.

2 University of Nottingham, Nottingham, United Kingdom, NG7 2RD.

${ }^{3}$ Raymond Purves Bone and Joint Research Laboratory, Kolling Institute Northern Sydney Local Health District, St. Leonards, NSW 2065, Australia.

${ }^{4}$ Sydney Medical School, Northern, The University of Sydney, Royal North Shore Hospital St. Leonards, NSW 2065, Australia. 


\begin{abstract}
Perlecan, or heparan sulfate proteoglycan 2 (HSPG2), is a ubiquitous heparan sulfate proteoglycan that has major roles in tissue and organ development and wound healing by orchestrating the binding and signaling of mitogens and morphogens to cells in a temporal and dynamic fashion. In this review, its roles in fibrosis are reviewed by drawing upon evidence from tissue and organ systems that undergo fibrosis as a result of an uncontrolled response to either inflammation or traumatic cellular injury leading to an over production of a collagen-rich extracellular matrix. This review focuses on examples of fibrosis that occurs in lung, liver, kidney, skin, kidney, neural tissues and blood vessels and its link to the expression of perlecan in that particular organ system.
\end{abstract}

\title{
Keywords
}

Fibrosis; proteoglycan; perlecan; heparan sulfate.

\begin{abstract}
Abbreviations
apoE, apolipoprotein E; $\alpha-S M A, \alpha$-smooth muscle actin; BMP1, bone morphogenic protein-1;CCL, CC chemokine ligand; COPD, chronic obstructive pulmonary disease; CS, chondroitin sulfate; CSPG4, chondroitin sulfate proteoglycan 4; CXCL, CXC chemokine ligand; DS, dermatan sulfate; ECM, extracellular matrix; EGF, epidermal growth factor; FGF, fibroblast growth factor; HS, heparan sulfate; HSC, hepatic stellate cell; HSPG2, heparan sulfate proteoglycan 2; IL, interleukin; IPF, idoiopathic pulmonary fibrosis; KS, keratan sulfate; LDL, low density lipoprotein; LG, laminin G-like domain; MAPK, mitogen-activated protein kinase; MMP, matrix metalloproteinase; NGF, neural growth factor; NG2, neural/glial antigen 2; PDGF, platelet-derived growth factor; PI3K, phosphoinositide 3-kinase, PRELP, proline-arginine-rich end leucine-rich repeat protein; PTEN, phosphatase and tensin homolog; SMC, smooth muscle cell; STAT, signal transducer and activator of transcription; SULF, sulfatase; TGF, transforming growth factor; VEGF, vascular endothelial growth factor.
\end{abstract}




\section{Introduction}

Fibrosis is a complex and finely tuned process that occurs in response to either inflammation, traumatic cellular injury or as a result of unknown or congenital issues affecting the structure of the extracellular matrix (ECM). Fibrosis is generally associated with pathological changes where significant increases in the expression and assembly of the ECM, notably the collagen content of the tissues. This has significant longer term impacts on the structural and functional properties of the tissues that may lead to impairment and failure of that organ. While the primary attributes seen in these diseases lie in the over-production of collagen in the tissues, changes in perlecan, also known as heparan sulfate proteoglycan 2 (HSPG2), levels also occur [1-3].

It is now well accepted that fibrosis is not a static event, but a dynamic process involving several phases that are also common to the wound healing response. Initially, an influx of inflammatory cells are seen that become activated resulting in the downstream activation of tissue resident ECM secreting cells followed by a significant change in the structure of ECM from an increased synthesis and decreased proteolytic turnover, further immune cell infiltration and delayed apoptosis $[4,5]$. Many of these phases involve heparin-binding growth factors, cytokines and chemokines suggesting that heparan sulfate (HS) proteoglycans play important roles in this process [6]. Despite the range of biological activities of $\mathrm{HS}$, there are only a few HS proteoglycans present in the ECM including perlecan, collagen type XVIII and agrin [7]. The abundance of perlecan in basement membranes and connective tissues that exhibit fibrosis $[7,8]$ as well as the key roles that it plays in many tissues suggests that it may play important roles in fibrosis. Recent evidence that will be reviewed in the following sections supports the hypothesis that perlecan plays key roles in the regulation of fibrogenesis.

\subsection{Overview of perlecan}

\subsubsection{Structure of perlecan}

Perlecan is a ubiquitous HS proteoglycan synthesized by most cells and present in most pericellular and extracellular matrices and is recognized as an essential component of basement membranes [7, 9]. Perlecan has also been localized to connective tissues and is produced by leukocytes [10]. The protein core of human perlecan is $460 \mathrm{kDa}$ and composed of five distinct domains with glycosaminoglycan attachment sites located in both the $\mathrm{N}$ - and $\mathrm{C}$-terminal domains (Fig. 1). Perlecan exerts tissue-specific activities through its glycosaminoglycan chains as the structure of these depends on the context and cell source. Typically, the three glycosaminoglycan attachment sites in domain I are decorated with HS, which has been shown for endothelial cell derived perlecan [11]. Perlecan may also be decorated with chondroitin and/or keratan sulfate (CS and KS respectively) in addition to HS as has been demonstrated for smooth muscle and epithelial cell derived perlecan [12-14] and these may also utilize the glycosaminoglycan attachment site in domain $\mathrm{V}$ [15]. There are many biological functions ascribed to perlecan including playing central roles in regulating the assembly of the ECM and the binding and presentation of growth factors to cells [16].

\subsubsection{Functions of the glycosaminoglycan chains}


The HS chains that decorate perlecan electrostatically interact with growth factors enabling their storage in the ECM, protection from proteolytic degradation and potentiation of their activity when bound to their cognate receptors $[17,18]$. The HS chains of perlecan, bind and modulate the signaling of fibroblast growth factors (FGF) 1, 2 and $18[13,14,19,20]$ and also bind to other heparin-binding growth factors that have been shown to be involved in the fibrotic process and include vascular endothelial growth factor (VEGF) isoforms 165, 189 and 206, epidermal growth factor (EGF), transforming growth factor (TGF) $\alpha$, connective tissue growth factor and hepatocyte growth factor (HGF) [6, 21]. Fine structural changes in the HS chains on perlecan can control growth factor signaling. For example, FGF1 signals when complexed with endothelial cell derived perlecan HS but not smooth muscle cell derived perlecan HS [13]. Additionally, cells have the ability to dynamically change the structure of their glycosaminoglycan chains as a result of the microenvironment [22] enabling temporal control over heparin-binding growth factor activities. The FGF2/perlecan complex is important in specifying the spatial distribution of the growth factor while degradation of perlecan destabilizes the complex causing FGF2 to lose its defined localization [23] in the ECM enabling it to interact with the syndecan and glypican families of cell surface HS proteoglycans [24]. The HS chains that decorate perlecan modulate the activity of mitogenic growth factors that support the proliferation of a wide variety of cell types including those involved in fibrosis [25-28]. At high cell densities in culture, the proliferation of many mesenchymal cell types was reduced by perlecan [25, 29,30], suggesting that the role of perlecan in these situations is complex and not well understood.

\subsubsection{Enzymatic regulation by heparanase and sulfatases}

The activity of heparin binding growth factors can be affected by the action of HS modifying enzymes including heparanase and the sulfatases. Heparanase cleaves HS both on the cell surface and in the basement membrane and has been shown to modulate FGF signaling [31, 32]. Heparanase expression is reduced during liver fibrosis and increased in atherosclerosis [14, 17, 33-35]. Sulfatases (SULF)-1 and -2 selectively remove 6-O-sulfate mainly from trisulfated disaccharide units (IdoA2S-GlcNS6S) within S-domains of heparin/HS, where many growth factors, including FGFs, bind. Pretreatment of heparin with SULF-2 has been shown to inhibit the binding of many heparin binding growth factors while treatment of complexes formed between heparin and growth factors can be released by treatment with SULF-2 [36]. In addition, SULF-1 inhibits growth factor binding to its receptor [37]. Interestingly, both SULF- 1 and -2 are regulated by transforming growth factor (TGF)- $\beta 1$ and are reported to be upregulated in pulmonary fibrosis [38]. Together these studies suggest a role for HS modifying enzymes in the regulation of growth factor signaling events in fibrosis.

\subsubsection{Roles of the protein core}

Perlecan possesses an $\alpha 2 \beta 1$ integrin binding site in domain $\mathrm{V}$ that mediates cell adhesion, while other putative cell adhesion sites reside in domains III and IV [13,39, 40]. In addition, domain III of mouse perlecan contains an RGD sequence that may interact with integrins [41]. Perlecan can support the proliferation of a wide variety of cell types including those involved in fibrosis [25-28]. Perlecan can also be anti-proliferative for cell types such as smooth muscle cells (SMCs) via both HS and protein 
core, particularly domain III [13,42], that is mediated by the tumor suppressor PTEN [43]. Perlecan can also bind some growth factors via its protein core including platelet-derived growth factor (PDGF) to domain III [44] and keratinocyte growth factor (also known as FGF7) to both domains III and V [45]. Low density lipoprotein (LDL) binds to perlecan domain II and this binding is modulated by HS [35, 46].

Proteolytic processing of perlecan by chymase, MMPs, and cathepsins which can cleave in perlecan domain IV has been reported to generate perlecan fragments encompassing endorepellin [10], which is a recombinant form of perlecan domain $V$ named due to its anti-angiogenic activities [47, 48]. Although endorepellin contains a glycosaminoglycan attachment site in its protein sequence it is devoid of a glycosaminoglycan chain [47], thus its activities are ascribed to the protein core. Endorepellin can be cleaved by BMP1/Tolloid-like proteases and cathepsin $L$ to release the laminin G-like domain $(L G) 3$ region that includes the $\alpha 2 \beta 1$ integrin binding site $[49,50]$. Inflammatory cells including mast cells produce alternatively spliced forms of perlecan with a relative increase in the amount of transcripts corresponding to domain $\mathrm{V}$ [51]. Together the various roles of the perlecan protein core suggest that perlecan may exert its roles in fibrosis through both the parent molecule and biologically active fragments.

\subsubsection{Roles in ECM organization}

Perlecan is an essential molecule in tissue and organ development with roles in ECM stabilization and the maintenance of the functional status of mature connective tissues [52]. Perlecan interacts with a diverse range of ECM components including fibronectin, laminin and many of the collagens coordinating the organization of a diverse array of structural glycoproteins and ECM proteins [17, 53]. For example, perlecan assists in collagen fibrillogenesis, largely through its pendant glycosaminoglycan chains $[54,55]$.

\section{Manifestations of fibrosis and the fundamental roles of perlecan}

Fibrosis can affect a number of different tissues and organs in the body including the lung, liver, skin, kidney, neural and vascular tissues. The fibrogenic response involves several phases of cell-based processes such as fibroblast and immune cell activation, immune cell infiltration and delayed apoptosis resulting in the accumulation of ECM, which is the accepted hallmark of the condition. The many roles of perlecan described above suggest that it has important roles to play in both modulating and promoting fibrogenesis. The roles of perlecan in fibrogenesis are reviewed in the following sections drawing upon evidence in the literature of tissue-specific examples. A summary of the known roles of perlecan and their impact on fibrogenesis are summarized in Fig. 1. 


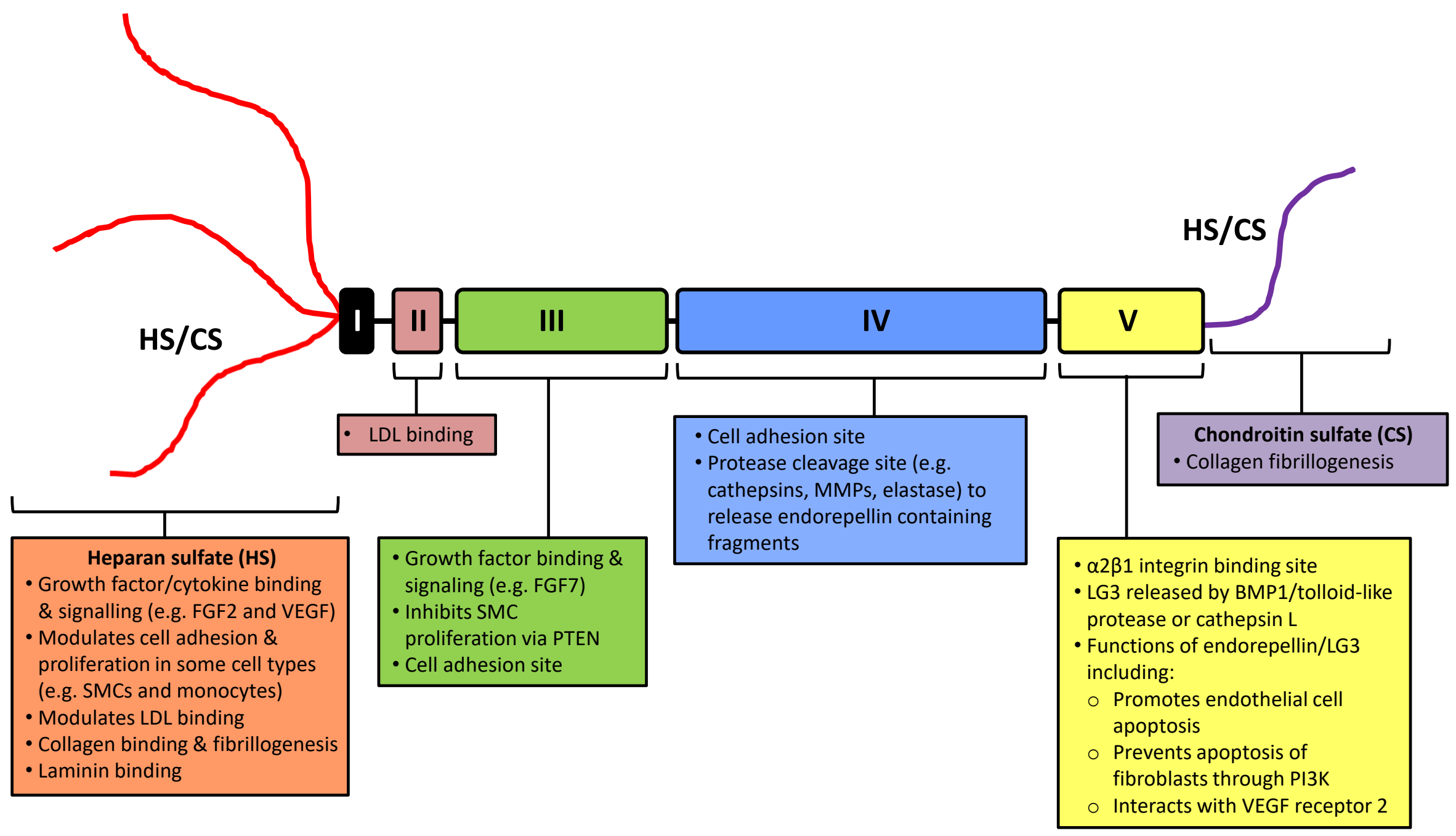

Fig. 1. Roles of perlecan in fibrogenesis mediated by both its protein core and glycosaminoglycan chains. 
A key event in the initiation of fibrosis is the activation of fibrocyte and fibroblast cells and their transdifferentiation to myofibroblastic-like cells that express $\alpha$-smooth muscle actin ( $\alpha-S M A)$. Interestingly, the activation of fibroblasts is not unique to fibrosis as it occurs in cancer, decidualization and infection [56-58]. The net accumulation of ECM in injured tissues results from the increased synthesis of ECM components including collagen types I and III, perlecan and laminins by cells [59]. Cells that infiltrate the injured site, including circulating inflammatory cells and fibrocytes, may also contribute to the synthesis of ECM locally; for example, monocyte-derived macrophages express perlecan in response to hypoxia mediated via the HIF-1a pathway [60] while macrophages and granulocytes have also been shown to produce perlecan $[10,60]$. Another example is the infiltration of mesenchymal stem cells and pericytes that potentially contribute to lung fibrosis that express the PDGF receptor $\alpha$ as well as fibrocytes of bone marrow origin [61] that home to sites of remodeling via CXC chemokine ligand (CXCL)12 and CXCR4 involving HS [62]. In ECM remodeling and repair, the myofibroblasts and fibroblasts are cleared through apoptosis [63]. However, during fibrosis the wound healing phase fails to terminate due to the lack of apoptosis of these cells and it has been hypothesized that the C-terminal fragment of perlecan directs cell apoptosis $[64,65]$.

Perlecan is involved in the generation of chemotactic growth factor and morphogen gradients which recruit cells to sites of ECM remodeling, primarily through interactions of the cytokines with its HS chains [66-70] but also including interactions of growth factors with its protein core [45]. Numerous cytokines including CC chemokine ligand (CCL) $-2,-3$ and -5 and CXCL-1, -8 (also known as interleukin (IL)-8), 9 and -10 and -12 (also known as stromal cell derived factor $1 \alpha$ ) bind HS/heparin [71-78] and their gradients in tissues are likely to be affected by the structure of the perlecan HS chains. These factors promote the migration of fibrogenic cells to the site of injury thereby amplifying inflammation [79]. This selective action suggests that perlecan may be involved in recruiting cell types that contribute to the organization of provisional matrix during tissue repair, and not those with a profibrotic phenotype, which would limit fibrosis [80].

TGF $\beta 1$ is one of the major cytokines involved in upregulating perlecan expression and it is expressed by many of the cell types involved in fibrogenesis in tissues including hepatic stellate cells (HSCs), fibroblasts, astrocytes and microglia, specialized brain macrophages [81-84]. The latent form of TGF $\beta 1$ is activated by plasmin that in turn upregulates perlecan expression $[85,86]$. There is also evidence of TGF $\beta 1$ regulating perlecan expression when endothelial cells are plated at high density, which may promote the repair of the injured endothelium in vivo [87].

Perlecan interacts with type IV collagen and a number of structural proteins to help form the basement membranes [88-90]. It assists in collagen fibrillogenesis, largely through its pendant CS chains [54], but there is evidence that this may also involve HS-dependent mechanisms [55]. Perlecan facilitates the interactions of laminin and collagen in conjunction with proline-arginine-rich end leucinerich repeat protein (PRELP), a collagen anchorage small leucine-rich proteoglycan, to create the basement membrane present in many tissues including those discussed in more detail in the next sections [91, 92]. 


\subsection{Lung}

In lung, chronic obstructive pulmonary disease (COPD), asthma and idiopathic pulmonary fibrosis (IPF) affect the parenchymal tissue manifesting as a thickening of the subepithelial ECM [93, 94]. While both COPD and IPF exhibit a progressive loss of alveolar parenchyma, COPD is an obstructive disease with airway inflammation and IPF is a restrictive disease [95]. The major ECM producing cells are fibroblasts and myofibroblasts while airway epithelial and SMCs are also involved [94, 96, 97] (Fig. 2A). Airway SMCs obtained from donors with COPD showed enhanced perlecan production following stimulation with TGF $\beta 1$ that was driven by intracellular SMAD activation [86]. Furthermore, this study demonstrated that COPD airway SMCs adhered to perlecan via epitopes in domains IV and V [86]. Interestingly, the ECM is degraded in the alveoli and excessive deposition in the bronchi and bronchioles that is correlated with differences in the fibroblast morphology, proliferation and ECM production [98]. Phenotypically different fibroblasts have been reported in central airways and lung parenchyma in COPD [99]. Fibroblasts in the parenchymal tissue were more sensitive to TGF $\beta 1$ expression than in the central airways, which resulted in increased VEGF synthesis, proliferation and increased the synthesis of perlecan [99, 100]. Fibrotic cells from biopsies taken from patients with asthmatic symptoms showed an increased secretion of perlecan in culture media compared to cells from normal patients [101]. In addition, cigarette smoke extract increased perlecan expression by COPD fibroblasts in vitro, however the mechanisms involved have not been explored [102].

In a rat model of bleomycin-induced pulmonary fibrosis, total proteoglycan content was significantly increased, including the expression level of perlecan [103]. Furthermore, primary lung fibroblast cultures established from rats after bleomycin induction exhibited increased production of perlecan, compared with normal lung fibroblasts together with a significant increase in the amount of TGF $\beta 1$ [104]. Incubation with an anti-TGF $\beta 1$ antibody inhibited proteoglycan expression in a dose-dependent manner, indicating that TGF $\beta 1$ was responsible in part for the increase in proteoglycan production in fibrotic cells [104]. Nitric oxide has been reported to downregulate perlecan expression in asthmatic lung fibroblasts [105]. Fibulin-1 peptides can stimulate the production of perlecan in lung derived airway SMCs and fibroblasts from patients with pulmonary fibrosis and COPD [106]. The augmented deposition of cell-associated perlecan together with fibronectin modulated by fibulin-1 may enhance fibroblast activity and extend fibroblast induced lung remodeling [106].

The structures of the HS chains decorating perlecan in lung tissue from patients with IPF showed increased levels of glycosaminoglycans as well as increased sulfation of the HS in the areas of increased matrix deposition linking these changes in glycosaminoglycan structure to the altered growth factor activity in fibrosis [107]. Immunohistochemical staining showed co-localization of perlecan and the highly sulfated HS, indicating perlecan may be the core protein that harbors these highly sulfated HS chains [107]. The altered HS composition in IPF may thus suggest that the ECM landscape in fibrosis favors growth factor activity and tissue remodeling [107]. 

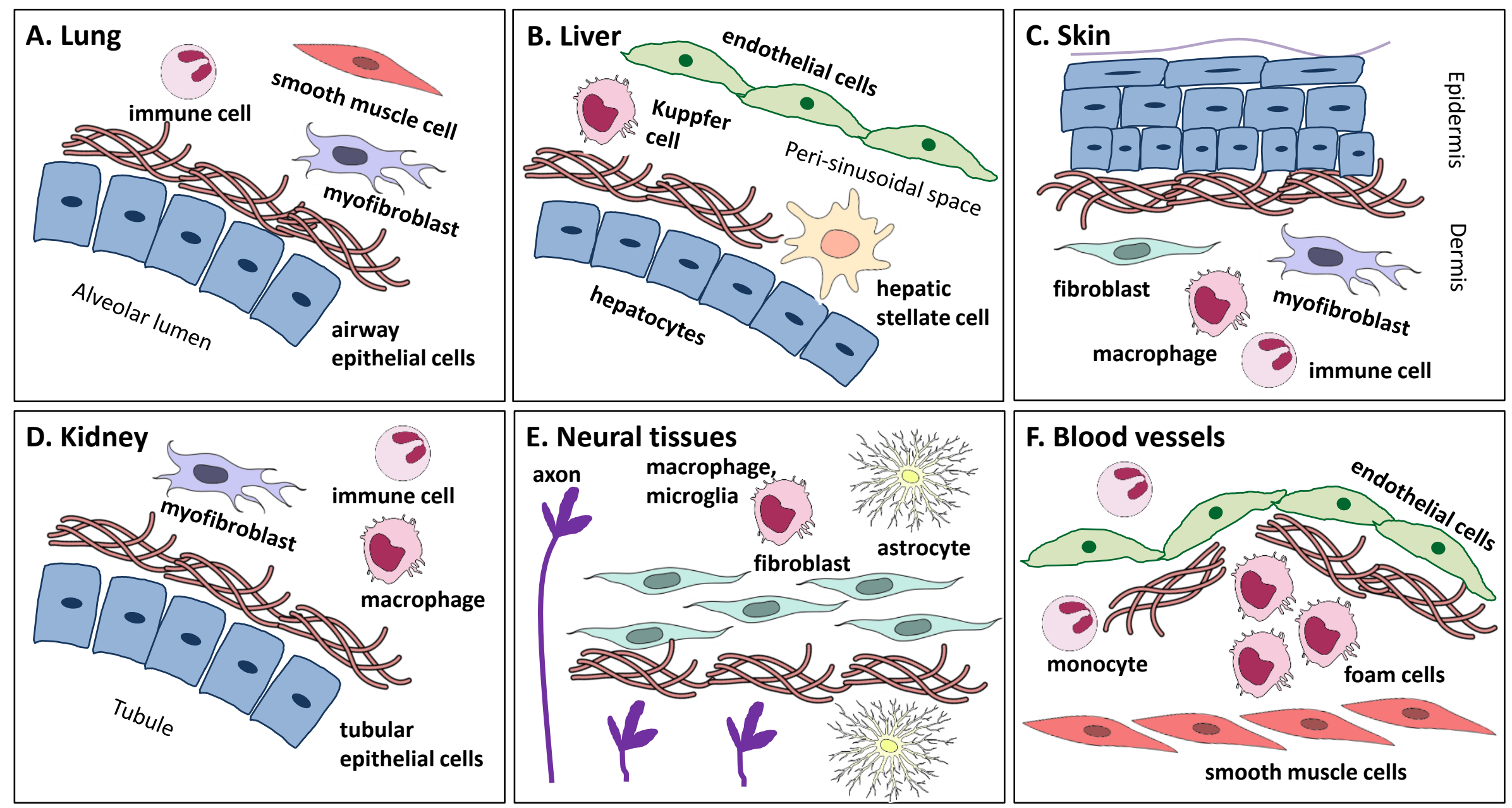

Fig. 2. Schematic of where fibrogenesis occurs and the cell types involved in (A) lung, (B) liver, (C) skin, (D) kidney, (E) neural tissues and (F) blood vessels. 


\subsection{Liver}

Hepatic endothelial cells line the space of Disse, which contains a non-continuous basement membrane due to a lack of polymerized laminin, which presumably facilitates the movement of cells and blood throughout and across the liver sinusoids (Fig. 2B). Despite the absence of polymerized laminin, this discontinuous membrane contained significant amounts of other ECM components including collagen, perlecan and fibronectin [2, 24, 108, 109]. In contrast, laminin is present together with collagen type IV in classical continuous basement membranes around liver biliary ducts and blood vessels [110]. In fibrosis, peri-sinusoidal basement membranes are synthesized and it has been shown that these contain laminin and collagen fibrils that are deposited, along with increased perlecan expression [2, 85, 108, 110-113]. The production of these basement membrane structures can cause functional changes that impact upon the exchange of macromolecules between the endothelial sinusoids and hepatocytes in the liver [93, 114, 115]. While perlecan is a major component of the perisinusoidal basement membrane in the liver, it along with type XVIII collagen is upregulated in fibrosis [2, 116].

The primary cells that are responsible for the deposition of the ECM in liver fibrosis are HSCs [4] that are resident peri-sinusoidal cells in the subendothelial space residing between the hepatocytes and sinusoidal endothelial cells. These cells become activated at sites of injury by factors produced by hepatocytes and endothelial cells, as well as infiltrating inflammatory cells including macrophages [117121]. Once activated HSCs exhibit increased mitogenic activity in the presence of PDGF-BB, a heparin binding growth factor that binds to perlecan HS and signals cells via the Ras-mitogen-activated protein kinase (MAPK) pathway via an upregulation of the PDGF- $\beta$ receptor $[17,29]$. The increased production and activity of cytokines are required for the continued activation of HSCs, which amplify inflammation through the release of neutrophil and monocyte chemo-attractants, such as monocyte chemotactic protein 1 (MCP-1) and colony-stimulating factor [122]. This positive feedback system results in an accumulation of HSCs and macrophages at the site of injury and it is interesting to note that activated HSCs respond to MCP-1 [123] that binds perlecan [124], demonstrating a level of cross talk in the system resulting in an accumulation of HSCs at the site.

Perlecan is upregulated in the periportal parenchyma during chronic cholestatic disease [24] and there is an increase in the HS and CS/dermatan sulfate (DS) content $[125,126]$ together with an upregulation of some of the enzymes involved in sulfate modification of HS including the 6-Osulfotransferases and glucosamine 3-O-sulfotransferase 1 enzymes involved in producing heparin-like sequences [126]. This supports the hypothesis that an increased abundance of these highly sulfated glycosaminoglycan sequences promote both collagen fibrillogenesis and laminin polymerization [54, $55,127]$.

Matrix metalloproteinase (MMP) activity is increased in fibrosis, particularly MMP-2,-3 and -9 , that degrades basement membrane components, including perlecan [94, 128-131], and replace this ECM with type I collagen which further activates cell growth and MMP production [132]. MMPs are derived from tissue resident cell populations, activated HSCs and Kupffer cells which are specialized liver macrophages [133]. 
In congenital hepatic fibrosis, there is a marked infiltration of mast cells scattered throughout the portal structures. These are more abundant than in other chronic liver diseases such as chronic viral hepatitis and alcoholic fibrosis [134] suggesting that mast cells might have a specific role in the congenital condition. It is tempting to speculate that it might involve the expression of the shorter forms of perlecan previously shown to be produced by mast cells $[10,51]$ which are produced by the actions of proteases secreted by mast cells including chymase or are a result of mRNA splicing and processing as shown for the mast cell line, HMC-1 [10].

\subsection{Skin}

The initiation of fibrosis in skin requires the epithelial cells in the epidermis to undergo an epithelial to mesenchymal transition, which converts the cell into an ECM expressing cell [94] (Fig. 2C). Perlecan is expressed throughout the epidermis and dermis of skin with a peri-cellular pattern with little demonstrable in the epithelial basement membrane. Aged keratinocytes have been reported to be perlecan deficient and were unable to form a multilayered epidermis with defects in cell proliferation and differentiation, suggesting that perlecan is a key modulator of cell proliferation [135]. Endorepellin has cell-signaling roles and was implicated as a key fibrogenic mediator [64]. Apoptosis of endothelial cells induces ECM proteolysis, and subsequently acts through phosphoinositide 3-kinase (PI3K) to prevent apoptosis in fibroblasts [65], implicating C-terminal fragments of perlecan in delaying fibroblast apoptosis. However, an increase in collagen secretion was not observed in response to endorepellin alone, indicating that additional apoptotic factors must act in a coordinated fashion to induce all features of myofibroblast differentiation [64]. Interestingly, human fibroblasts derived from sclerodermia skin lesions were more sensitive to the action of endorepellin than fibroblasts derived from healthy control skin [64], indicating a disease specific response to perlecan signaling.

\subsection{Kidney}

Renal fibrosis occurs in chronic nephropathies, leading to changes to the tubular and glomerular basement membranes and interstitial ECM resulting in decreased kidney function and eventually failure [136] (Fig. 2D). Kidney infections, toxins, mechanical obstruction, immune complexes resulting from autoimmune diseases or chronic infections and genetic disorders lead to cellular injury while type-2 diabetes mellitus and ischemic/hypertensive nephropathy also contribute to kidney fibrogenesis [137]. Fibrotic changes in the kidney can also be caused by genetic mutations such as Denys-Drash syndrome from mutations in the WT1 gene that causes an initial decrease in perlecan expression that is later reversed and increases along with collagen type IV, laminin, fibronectin and tenascin and results in mesangial sclerosis [96]. In the kidney, the major HS proteoglycan in the glomerular basement membrane is agrin [138] while perlecan plays a major role in filtration in the glomeruli [139] and has been correlated with a slower progression of IgA nephropathy [140]. Decreased amounts of perlecan have been shown in animal models of diabetic nephropathy as well as in diabetic patients [141]. Perlecan is also decreased in glomerular nephritis and IgA nephropathy whereas biglycan and decorin are both up regulated with a concomitant upregulation of TGF $\beta$ suggesting that a positive autocrine loop plays a major role in the expansion of the mesangial matrix [140]. Further, in an animal model of 
diabetic nephropathy streptozotocin elevated levels of TGF $\beta$ and was a major factor in the up-regulation of tissue fibrosis [142]. An increase in collagen types I, III and IV and fibronectin accompanied the decreased expression of perlecan in this model [143].

In sclerotic lesions of focal glomerulosclerosis in a rat renal transplant model, an induction of perlecan expression in the glomerular basement membrane was detected compared with its expression in control kidneys [144]. The observed induction of perlecan expression was also observed in the interstitium in a capillary-like pattern. Kidney allografts also presented extensive lymphangiogenesis, associated with induced perlecan expression underneath the lymphatic endothelium. The magnitude of lymphangiogenesis and perlecan expression both correlated with severity of interstitial fibrosis and impaired graft function [144].

\subsection{Glial scarring in neural tissues}

Glial scarring can arise in neural tissues that have undergone physical injury due to trauma including injury to the spinal cord or an hypoxic insult as a result of ischemia or cerebral stroke. In neural tissues, astrocytes, oligodendrocytes, Schwann cells and microglia, specialized brain macrophages, are the major cell types involved in the production of ECM components and assembly of myelin $[145,146]$ (Fig. $2 \mathrm{E})$. The microglia and astrocytes have major roles in fibrosis after becoming activated in response to the release of inflammatory cytokines such as IL-1 $\beta$ and TGF $\beta[145,146]$. These cytokines cause further release of proinflammatory cytokines and an upregulation of ECM molecules, most notably CS lectican proteoglycans including aggrecan, versican, neurocan, brevican [147] and phosphacan [145, 146]. Perlecan has a central role in the developing brain by regulating neurogenesis through the control of neural cell position and phenotype in regions of the developing brain [148, 149].

The CS proteoglycans present in the glial scar surrounding the lesion site prevent neurite outgrowth in vitro and nerve regeneration in vivo [150]. A recent transcriptomic analysis of astrocytes stimulated with IL-1 $\beta$ showed no evidence of upregulation of any of the CS proteoglycan genes suggesting that they were not the only proteoglycans in the glial scar [151]. Rat cortical astrocytes were shown to produce more HS than CS in culture with a relatively higher content of unsubstituted glucosamine disaccharides. The glycosaminoglycan chains of higher negative charge were more effective at stimulating nerve growth factor (NGF) signaling in PC12 cells but the protein core to which the HS was attached was not investigated [152]. The heparin binding domain of laminin is responsible for neurite outgrowth together with NGF [127] implicating HS proteoglycans in this process. The C-terminal domain $\checkmark$ region of perlecan delayed the onset of glial scarring in rat models by decreasing the expression of neurocan and phosphacan and stimulating the activity of NGF [153]. These data suggest that the balance between CS and HS proteoglycans in the ECM and the alteration in this balance changes the nature of the surrounding environment, which can either inhibit or stimulate neurite outgrowth and nerve regeneration [154].

While the laminin-like $G$ domain (LG)3 fragment, as yet, has not been associated with the formation of glial scarring, mice deficient of neural/glial antigen 2 (NG2)/chondroitin sulfate proteoglycan 4 (CSPG4) had a reduced amount of glial scarring and were more permissive to axonal regrowth [155]. Interestingly these animals had a similar phenotype to the progranulin deficient animals [155]. 
Progranulin is a neuroprotective molecule [156] that binds to the C-terminal region of perlecan and specifically to the first two laminin like repeats LG1 and LG2 [157]. A recent study indicated that the Cterminal region of perlecan binds to CSPG4 [158] and it is tempting to speculate that this binding involves an intermediate interaction with progranulin. Interestingly, this same C-terminal region of perlecan is neuroprotective and pro-angiogenic in a rat ischemic model [159].

\subsection{Blood vessels and vascular tissues}

Atherosclerosis is characterized by intimal thickening due to an over production of ECM and lipid accumulation in the intima as well as macrophage activation and foam cell formation [160, 161] (Fig. $2 \mathrm{~F}$ ). Monocyte recruitment, retention and differentiation play a central role in the development of atherosclerosis [161] and removal of HS increased the association of monocytes with the subendothelial matrix [35] suggesting that HS may inhibit monocyte interactions with the ECM by inhibiting cell-surface integrin interactions $[162,163]$. The initial activation of SMCs after arterial injury is coupled with a decrease in the expression of laminin and basement membrane-like structures, whereas fibronectin accumulates around proliferating cells in the arterial media and intima [164]. Perlecan can act directly on fibrocyte-like cell activation through promotion of cell adhesion or indirectly via binding and potentiating the signaling of growth factors and cytokines involved in cell activation and proliferation [165]. Non-human primates fed a diet to induce hypercholesterolemia demonstrated atherosclerotic lesions with perlecan associated with the media in normal vessels and early stages of lesion formation and was prominent in the SMC matrix near the plaque core of more advanced lesions [166]. These observations indicate that basement membrane components, including perlecan, may take part in the regulation of the differentiated state of ECM producing cells [167].

The progression and organization of the developing plaque in blood vessels, including migration and proliferation of SMCs into the intima, results in the secretion of collagen and the formation of a fibrous cap that surrounds the lipid rich core of the plaque. Perlecan is thought to have pro-atherogenic effects by retaining lipoproteins in the matrix in the early phase of atherosclerosis $[46,168]$. Perlecan supports low density lipoprotein (LDL) sequestration via its protein core, notably domain II, while HS modulates this binding $[35,46]$, a key effect in the progression of atherogenesis.

Vascular SMC proliferation occurs via FGF2 and suggests a role for perlecan in the downregulation of the FGF2 mediated proliferative response as demonstrated by the HS chains that decorate SMC derived perlecan did not potentiate the growth signal of FGFs [13]. Removal of HS, through the action of the HS degrading enzyme heparanase [169], from late vascular lesion explants supported the proliferation of neointimal SMCs and rendered them responsive to PDGF [17, 170]. FGF2 is also induced by PDGF treatment of SMCs, further supporting the role of FGF2 in the proliferation of SMCs [171]. While perlecan is often thought of as a pro-atherogenic molecule [172], vascular SMC activation and proliferation is inhibited by perlecan $[170,173,174]$ and it is the lack of perlecan expression in early initiation of atherosclerosis that enables SMC activation, proliferation and ECM synthesis [170]. When SMCs are present in high density, thrombin can promote perlecan synthesis $[175,176]$ and may act in concert with mechanical strain and angiotensin II [177-179]. This suggests that perlecan expression is tightly linked to limiting SMC activation and proliferation. In the vasculature this suppression of SMC 
activation is mediated by thrombin and factor Xa [177]. The mechanisms by which perlecan is antiproliferative for vascular SMCs is via both HS and protein core, particularly domain III [13, 42], that is mediated by the tumor suppressor phosphatase and tensin homolog (PTEN), which inhibits growth factor receptor signaling [43]. Furthermore, perlecan has been implicated in inhibiting growth of vascular SMCs via Oct-1, a member of a family of transcription factors involved in cell growth processes and suggest that breakdown of the basement membrane and loss of interaction with perlecan activates cells from their quiescent state [173]. Plaque development is also attributed to the HS chains on perlecan as demonstrated by mice lacking $\mathrm{HS}$ in the $\mathrm{N}$-terminal domain of perlecan on an ApoE-deficient background exhibit reduced plaque development [172]. Thus the ability of perlecan to suppress SMC proliferation may contribute to plaque instability as it is the SMCs that produce the fibrous cap that stabilizes the lipid plaques.

Cadmium is an environmental risk factor for atherosclerosis and has been found to induce changes in the expression of endothelial perlecan with markedly shorter HS chains that were able to stimulate the proliferation of vascular SMCs in the presence of FGF2 [180]. Heparin has also been reported to upregulate perlecan expression in vascular SMCs [42] and hypothesized to promote FGF2 signaling. Perlecan expression is increased in late stages of atherosclerosis and modulated by apolipoprotein $E$ (apoE) $[59,174]$ as demonstrated by reduced perlecan expression in apoE deficient mice [160]. A murine model of atherosclerosis exhibited enhanced perlecan expression in apoE deficient mice fed a chow diet and was expressed in both early and advanced plaques [181]. Nitric oxide may be an important intermediate signaling molecule in the induction of perlecan by apoE in SMCs as both are required for the modulation of SMC proliferation [174].

Myeloperoxidase and peroxynitrous acid released from activated leukocytes selectively degrade the core protein of perlecan $[182,183]$. The precise degradation site(s) on the core protein await identification however, there is evidence for the presence of peroxynitrite-modified perlecan fragments in human atherosclerotic lesions [184]. Proteolytic processing of perlecan by chymase, MMPs, and cathepsins which can cleave in perlecan domain IV has been reported to generate perlecan fragments encompassing endorepellin [47]. Endothelial cell apoptosis triggers a caspase-dependent release of the LG3 containing fragment of perlecan suggesting that proteases are responsible for the cleavage of perlecan to release this bioactive fragment. This fragment supports the proliferation of vascular SMCs and fibroblasts and inhibits their apoptosis [185] through PI3K [65], whilst increasing the expression of aSMA through OI3K and collagen types I and III expression in these cells [49, 63, 64]. Interestingly, the EGF peptide motif in perlecan domain $V$ together with 4-sulfated CS could replicate this inhibition of apoptosis of fibroblasts and vascular SMC [64]. However, an increase in collagen secretion was not observed in response to endorepellin alone, indicating that additional apoptotic factors act coordinately to induce all features of myofibroblast differentiation [185].

Endorepellin interacts with VEGF receptor 2 providing evidence for its ability to control cell adhesion and VEGF-mediated mitogenic activities [186]. The C-terminal domain V of perlecan has either antiangiogenic $[187,188]$ or angiogenic $[10,15]$ activities in line with the action of the parent molecule. Endorepellin has been shown to be anti-angiogenic when added to cultures of endothelial cells by either interfering with the interactions between VEGF receptor 2 and the LG1/2 regions in domain V [189] or 
sterically competing with the $\alpha 2 \beta 1$ integrin mechanism of attachment in domain $\mathrm{V}$ [39]. Endorepellin binds to the $\mathrm{N}$-terminal fragment of type XVIII collagen, known as endostatin, where it counteracts its anti-angiogenic activities [47].

Interestingly, TGF $\beta$ is upregulated during the initiation of early atherosclerosis when perlecan expression is downregulated, potentially by PDGF that decreases perlecan expression in the vasculature [190], suggesting that in the vasculature, perlecan expression is regulated independently of TGF $\beta$ expression [191]. Concomitant with this decrease in perlecan expression is an increase in the levels of CS/DS proteoglycans [160]. Oxidized LDL and lysolecithin, a product of LDL oxidation, both decrease endothelial HS proteoglycan expression [35]. While the mechanism is unclear, activation of signal transducer and activator of transcription 1 (STAT1) are key signaling molecules involved in inhibition of perlecan transcription by oxidants and inflammatory cytokines [35].

Restenosis is a scarring that occurs in the vasculature following a vascular intervention and involves a change in phenotype of the quiescent contractile SMCs to proliferate and produce ECM [192]. This is accompanied by a downregulation of their contractile proteins, which is in contrast to fibroblasts in fibrosis which upregulate aSMA to become myofibroblasts [193]. Perlecan expression has been reported to be low in uninjured blood vessels and immediately following injury which corresponded to maximal SMC proliferation, while perlecan has been reported to increase later in advanced lesions that coincided with an arrest of SMC proliferation [170]. Interestingly, heparinase treatment promoted SMC growth [170] suggesting that the temporal expression of perlecan is important for fibrogenesis.

The length and sulfation pattern of perlecan HS chains are cell type specific [194], and it is therefore likely that these features play a role in the tissue-specific functions of perlecan. Deletion of the glycosaminoglycan attachment sites in domain I of mouse perlecan supported the proliferation of SMCs following flow cessation of the carotid artery [195] further supporting the role of both the HS and perlecan protein core in the modulation of SMC activation and proliferation. In a separate study, HS proteoglycans were more effective in inhibiting neointima formation in a rabbit model of restenosis than heparin [196] supporting the synergistic role of HS together with the perlecan protein core. These studies indicate that during tissue remodeling perlecan promotes desirable cell proliferation whilst simultaneously inhibiting undesirable proliferation activities of SMCs.

\section{Therapies for fibrosis that alter perlecan expression}

While therapies exist which delay fibrogenesis, the contribution of these treatments to the structure or abundance of perlecan in fibrosis is less clear. Of the fibrosis treatments explored, sulodexide, a mixture of non-anticoagulant low molecular weight heparin/HS and DS, has been shown to increase perlecan expression in a rat model of diabetic nephropathy, whilst the expression of collagens I and IV decreased suggesting that TGF $\beta$ may be controlled by interacting with the glycosaminoglycans [143]. Additionally, in vitro culture of tubular cells treated with sulodexide reduced expression of aSMA, heparanase-1 and MMP9 suggesting that this treatment inhibited the epithelial-mesenchymal transition characteristic of fibrosis [197]. Additionally, perlecan expression is upregulated via treatment of murine atherosclerosis with telmisartan, an angiotensin II receptor antagonist [198]. 
With the concept of the multifaceted roles of perlecan in fibrosis, the effect of the following fibrosis treatments warrant further investigation for their effect on perlecan expression. Nintedanib, a tyrosine kinase inhibitor, is approved for the treatment of IPF [199]. It inhibits a variety of receptors including the PDGF receptor, VEGF receptors 1 and 2, and FGF receptors 1-3 [200] and affects the binding partners for perlecan that are involved in cell proliferation in fibrosis, although analysis of the effect on perlecan expression has not been examined. Nintedanib inhibits the progression of processes in fibrosis including the migration of fibroblasts, their transformation into myofibroblasts and the deposition of extracellular matrix $[201,202]$ thus it is possible to speculate that this treatment affects perlecan expression. Through a similar approach, sorafenib targets the PDGF receptor and is effective in reducing fibrosis in animal models of liver fibrosis [203] and many also affect perlecan expression.

Adenoviral vectors expressing an antisense mRNA of the PDGF $\beta$-chain delivered to an animal model of induced liver fibrogenesis down-regulated endogenous PDGF $\beta$-chain expression [204, 205], which is likely to lead to increased perlecan expression [190] with a positive outcome for modulating the progression of fibrosis. Pirfenidone inhibits TGF $\beta 1$ stimulated collagen expression [206] and in vitro experiments have shown that it can inhibit the proliferation of HSCs and lung fibroblasts [207-209] and is thus worthy of further exploration for its effect on perlecan expression.

Statins are effective in lowering LDL cholesterol [210] and also reduced plaque volume when used at high dose [210]. ApoE deficient mice treated with statins also display reduced plaque volume with increased decorin and biglycan expression and a more condensed collagen rich ECM, however perlecan expression was not altered in these mice [211] even though it has a major role in LDL retention and has been shown to modulate HS proteoglycan expression [35]. The renin-angiotensin system (RAS) is a central regulatory system for cardiovascular function and critically connected to atherosclerosis and mediated by angiotensin II. RAS blockade has been shown to attenuate the progression of atherosclerotic lesions in animals and is thus a promising therapy for human cardiovascular diseases [191]. A novel perlecan-inducing compound, RUS310, is a potent inhibitor of SMC activity and has been trialed for the treatment of in-stent restenosis [212]. So far this compound has not been trialed for the treatment of fibrosis, but may be a rewarding approach to modulate perlecan expression.

\section{Final Considerations}

The literature provides ample evidence for the roles of perlecan in controlling / modulating fibrogenesis (Fig. 1). Perlecan has key roles in promoting tissue repair whilst limiting damaging fibrosis even though many of the tissue repair activities can also contribute to fibrogenesis if not resolved in a timely fashion (Fig. 3). The anti-fibrotic activities of perlecan are mediated through modulating cell adhesion, proliferation and migration of key inflammatory and ECM producing cells. In contrast, perlecan contributes to fibrogenesis through growth factor binding and signaling, LDL binding, ECM interactions and activities of the $\mathrm{C}$-terminal region of perlecan that inhibit the apoptosis of fibroblasts. These multifaceted roles of perlecan suggest that it plays a role in each phase of fibrogenesis, with particularly important roles in modulating the activity of growth factors, chemokines and cytokines for 
cell activation, infiltration and proliferation. These activities can be attributed to either the glycosaminoglycan or protein core components of perlecan. The glycosaminoglycan chains change dynamically as a result of changes in the microenvironment enabling temporal and spatial control over growth factor, chemokine and cytokine activity. While the precise mechanisms involved in the roles of perlecan involved in fibrogenesis remain unclear, the current evidence suggests that it is an important candidate worthy of further development of more effective treatments for fibrosis.

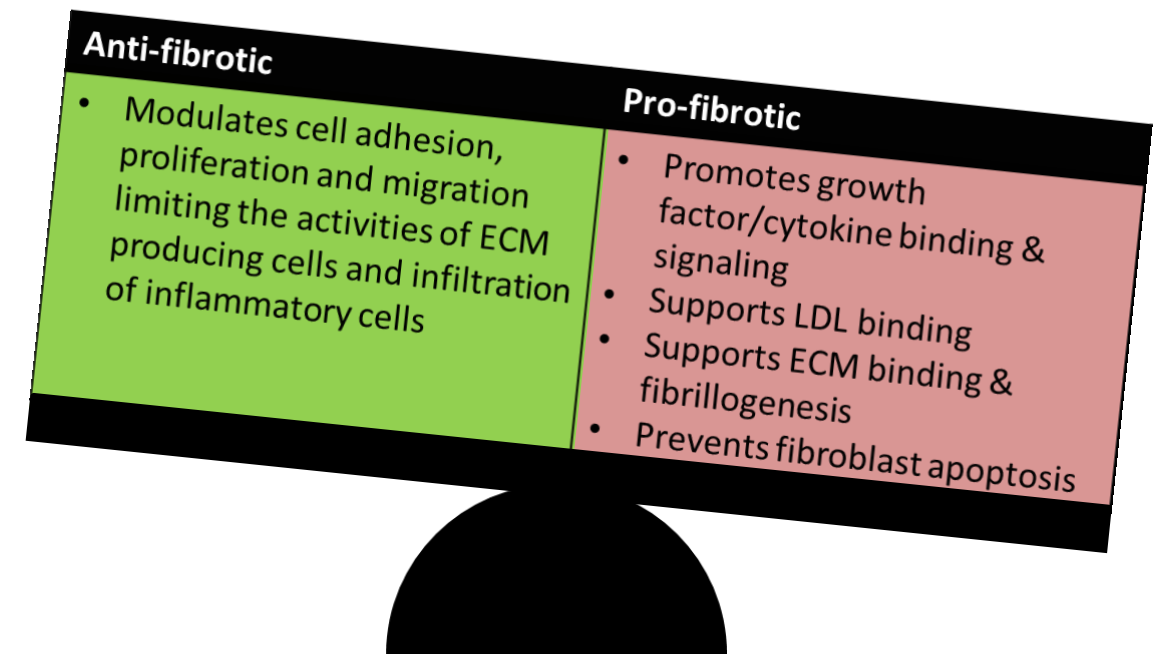

Fig. 3. The anti- and pro-fibrotic activities of perlecan that are open to therapeutic manipulation.

\section{Acknowledgements}

The authors acknowledge funding by the Australian Research Council (DP150104242 and LP140101056). Figures were prepared with the assistance of Mind the Graph.

\section{References}

[1] I. Kovalszky, P. Nagy, B. Szende, K. Lapis, F. Szalay, A. Jeney, Z. Schaff, Experimental and human liver fibrogenesis, Scand J Gastroenterol Suppl 228 (1998) 51-5.

[2] K.M. Mak, R. Mei, Basement membrane type IV collagen and laminin: An overview of their biology and value as fibrosis biomarkers of liver disease, Anat Rec 300 (2017) 1371-1390.

[3] S. Yung, T.M. Chan, Glycosaminoglycans and proteoglycans: overlooked entities?, Perit Dial Int 27 Suppl 2 (2007) S104-9.

[4] U.E. Lee, S.L. Friedman, Mechanisms of hepatic fibrogenesis, Best Pract Res Clin Gastroenterol 25 (2011) 195-206.

[5] J. Melrose, Glycosaminoglycans in Wound Healing, Bone Tissue Regener Insights 7 (2016) BTRI.S38670.

[6] S. Ashikari-Hada, H. Habuchi, Y. Kariya, N. Itoh, A.H. Reddi, K. Kimata, Characterization of Growth Factor-binding Structures in Heparin/Heparan Sulfate Using an Octasaccharide Library, J Biol Chem 279 (2004) 12346-12354.

[7] R.V. lozzo, L. Schaefer, Proteoglycan form and function: A comprehensive nomenclature of proteoglycans, Matrix Biol 42 (2015) 11-55.

[8] A. Pozzi, P.D. Yurchenco, R.V. lozzo, The nature and biology of basement membranes, Matrix Biol 57-58 (2017) 1-11. 
[9] M.C. Farach-Carson, C.R. Warren, D.A. Harrington, D.D. Carson, Border patrol: insights into the unique role of perlecan/heparan sulfate proteoglycan 2 at cell and tissue borders, Matrix Biol 34 (2014) 64-79.

[10] M. Jung, M.S. Lord, B. Cheng, J.G. Lyons, H. Alkhouri, J.M. Hughes, S.J. McCarthy, R.V. lozzo, J.M. Whitelock, Mast cells produce novel shorter forms of perlecan that contain functional endorepellin: a role in angiogenesis and wound healing, J Biol Chem 288 (2013) 3289-304.

[11] S. Knox, M. J., J. Whitelock, Electrophoretic, biosensor, and bioactivity analyses of perlecans of different cellular origins., Proteomics 1 (2001) 1534-1541.

[12] S. Knox, A.J. Fosang, K. Last, J. Melrose, J. Whitelock, Perlecan from human epithelial cells is a hybrid heparan/chondroitin/keratan sulfate proteoglycan, FEBS Lett 579 (2005) 50195023.

[13] M.S. Lord, C.Y. Chuang, J. Melrose, M.J. Davies, R.V. lozzo, J.M. Whitelock, The role of vascular-derived perlecan in modulating cell adhesion, proliferation and growth factor signaling, Matrix Biol 35 (2014) 112-22.

[14] C.Y. Chuang, M.S. Lord, J. Melrose, M.D. Rees, S.M. Knox, C. Freeman, R.V. lozzo, J.M. Whitelock, Heparan Sulfate-Dependent Signaling of Fibroblast Growth Factor 18 by Chondrocyte-Derived Perlecan, Biochemistry 49 (2010) 5524-5532.

[15] J. Rnjak-Kovacina, F. Tang, J.M. Whitelock, M.S. Lord, Silk biomaterials functionalized with recombinant domain $\mathrm{V}$ of human perlecan modulate endothelial cell and platelet interactions for vascular applications, Colloid Surf B 148 (2016) 130-138.

[16] J.R. Bishop, M. Schuksz, J.D. Esko, Heparan sulphate proteoglycans fine-tune mammalian physiology, Nature 446 (2007) 1030-7.

[17] J.M. Whitelock, J. Melrose, R.V. lozzo, Diverse cell signaling events modulated by perlecan, Biochemistry 47 (2008) 11174-83.

[18] J.D. Esko, S.B. Selleck, Order out of chaos: assembly of ligand binding sites in heparan sulfate, Annu Rev Biochem 71 (2002) 435-71.

[19] S. Knox, C. Merry, S. Stringer, J. Melrose, J. Whitelock, Not all perlecans are created equal Interactions with fibroblast growth factor (FGF) 2 and FGF receptors, J Biol Chem 277 (2002) 14657-14665.

[20] J. Melrose, P. Roughley, S. Knox, S. Smith, M. Lord, J. Whitelock, The Structure, Location, and Function of Perlecan, a Prominent Pericellular Proteoglycan of Fetal, Postnatal, and Mature Hyaline Cartilages, J Biol Chem 281 (2006) 36905-36914.

[21] T. Cohen, H. Gitay-Goren, R. Sharon, M. Shibuya, R. Halaban, B. Levi, G. Neufeld, VEGF121, a vascular endothelial growth factor (VEGF) isoform lacking heparin binding ability, requires cell-surface heparan sulfates for efficient binding to the VEGF receptors of human melanoma cells, J Biol Chem 270 (1995) 11322-11326.

[22] M.S. Lord, M. Jung, J.M. Whitelock, Optimization of bioengineered heparin/heparan sulfate production for therapeutic applications, Bioengineered (2017) 1-4.

[23] J.I. Mollmark, A.J. Park, J. Kim, T.Z. Wang, S. Katzenell, S.L. Shipman, L.G. Zagorchev, M. Simons, M.J. Mulligan-Kehoe, Fibroblast growth factor-2 is required for vasa vasorum plexus stability in hypercholesterolemic mice, Arterioscler Thromb Vasc Biol 32 (2012) 2644-51.

[24] T. Roskams, J. Rosenbaum, R.D. Vos, G. David, V. Desmet, Heparan sulfate proteoglycan expression in chronic cholestatic human liver diseases, Hepatology 24 (1996) 524-532.

[25] R. Nakamura, F. Nakamura, S. Fukunaga, Perlecan Diversely Regulates the Migration and Proliferation of Distinct Cell Types in vitro, Cells, tissues, organs 200 (2015) 374-93.

[26] D. Aviezer, D. Hecht, M. Safran, M. Eisinger, G. David, A. Yayon, Perlecan, basal lamina proteoglycan, promotes basic fibroblast growth factor-receptor binding, mitogenesis, and angiogenesis, Cell 79 (1994) 1005-13.

[27] B. Sharma, M. Handler, I. Eichstetter, J.M. Whitelock, M.A. Nugent, R.V. lozzo, Antisense targeting of perlecan blocks tumor growth and angiogenesis in vivo, J Clin Invest 102 (1998) 1599-608.

[28] K. Sakai, K. Oka, K. Matsumoto, T. Nakamura, p27 Nuclear localization and growth arrest caused by perlecan knockdown in human endothelial cells, Biochem Biophys Res Commun 392 (2010) 403-8.

[29] A. Andersson-Sjoland, L. Thiman, K. Nihlberg, O. Hallgren, S. Rolandsson, I. Skog, L. Mared, L. Hansson, L. Eriksson, L. Bjermer, G. Westergren-Thorsson, Fibroblast phenotypes and their activity are changed in the wound healing process after lung transplantation, J Heart Lung Transplant 30 (2011) 945-54. 
[30] U. Hedin, B.A. Bottger, E. Forsberg, S. Johansson, J. Thyberg, Diverse effects of fibronectin and laminin on phenotypic properties of cultured arterial smooth muscle cells, J Cell Biol 107 (1988) 307-319.

[31] I. Matsuo, C. Kimura-Yoshida, Extracellular modulation of Fibroblast Growth Factor signaling through heparan sulfate proteoglycans in mammalian development, Curr Opin Genet Dev 23 (2013) 399-407.

[32] V.N. Patel, S.M. Knox, K.M. Likar, C.A. Lathrop, R. Hossain, S. Eftekhari, J.M. Whitelock, M. Elkin, I. Vlodavsky, M.P. Hoffman, Heparanase cleavage of perlecan heparan sulfate modulates FGF10 activity during ex vivo submandibular gland branching morphogenesis, Development 134 (2007) 4177-86.

[33] J.M. Whitelock, R.V. lozzo, Heparan sulfate: A complex polymer charged with biological activity, Chem Rev 105 (2005) 2745-2764.

[34] M. Ikeguchi, Y. Hirooka, N. Kaibara, Heparanase gene expression and its correlation with spontaneous apoptosis in hepatocytes of cirrhotic liver and carcinoma, Eur J Cancer 39 (2003) 86-90.

[35] S. Pillarisetti, L. Paka, J.C. Obunike, L. Berglund, I.J. Goldberg, Subendothelial retention of lipoprotein (a). Evidence that reduced heparan sulfate promotes lipoprotein binding to subendothelial matrix, J Clin Invest 100 (1997) 867-874.

[36] K. Uchimura, M. Morimoto-Tomita, A. Bistrup, J. Li, M. Lyon, J. Gallagher, Z. Werb, S.D. Rosen, HSulf-2, an extracellular endoglucosamine-6-sulfatase, selectively mobilizes heparinbound growth factors and chemokines: effects on VEGF, FGF-1, and SDF-1, BMC Biochem 7 (2006) 2.

[37] K. Narita, J. Staub, J. Chien, K. Meyer, M. Bauer, A. Friedl, S. Ramakrishnan, V. Shridhar, HSulf-1 inhibits angiogenesis and tumorigenesis in vivo, Cancer Res 66 (2006) 6025-32.

[38] X. Yue, J. Lu, L. Auduong, M.D. Sides, J.A. Lasky, Overexpression of Sulf2 in idiopathic pulmonary fibrosis, Glycobiol 23 (2013) 709-719.

[39] G. Bix, J. Fu, E.M. Gonzalez, L. Macro, A. Barker, S. Campbell, M.M. Zutter, S.A. Santoro, J.K. Kim, M. Höök, C.C. Reed, R.V. lozzo, Endorepellin causes endothelial cell disassembly of actin cytoskeleton and focal adhesions through $\alpha 2 \beta 1$ integrin, J Cell Biol 166 (2004) 97109.

[40] M.C. Farach-Carson, A.J. Brown, M. Lynam, J.B. Safran, D.D. Carson, A novel peptide sequence in perlecan domain IV supports cell adhesion, spreading and FAK activation, Matrix Biol 27 (2008) 150-60.

[41] S. Chakravarti, T. Horchar, B. Jefferson, G.W. Laurie, J.R. Hassell, Recombinant Domain III of Perlecan Promotes Cell Attachment through Its RGDS Sequence, J Biol Chem 270 (1995) 404-409.

[42] M.C.M. Weiser, J.K. Belknap, S.S. Grieshaber, M.G. Kinsella, R.A. Majack, Developmental regulation of Perlecan gene expression in aortic smooth muscle cells, Matrix Biol 15 (1996) 331-340.

[43] P.J. Garl, J.M. Wenzlau, H.A. Walker, J.M. Whitelock, M. Costell, M.C. Weiser-Evans, Perlecan-induced suppression of smooth muscle cell proliferation is mediated through increased activity of the tumor suppressor PTEN, Circ Res 94 (2004) 175-83.

[44] W. Gohring, T. Sasaki, C.H. Heldin, R. Timpl, Mapping of the binding of platelet-derived growth factor to distinct domains of the basement membrane proteins BM-40 and perlecan and distinction from the BM-40 collagen-binding epitope, Eur J Biochem 255 (1998) 60-6.

[45] M. Mongiat, K. Taylor, J. Otto, S. Aho, J. Uitto, J.M. Whitelock, R.V. lozzo, The protein core of the proteoglycan perlecan binds specifically to fibroblast growth factor-7, J Biol Chem 275 (2000) 7095-100.

[46] Y.-X. Xu, D. Ashline, L. Liu, C. Tassa, S.Y. Shaw, K. Ravid, M.D. Layne, V. Reinhold, P.W. Robbins, The glycosylation-dependent interaction of perlecan core protein with LDL: implications for atherosclerosis, J Lipid Res 56 (2015) 266-276.

[47] M. Mongiat, S.M. Sweeney, J.D. San Antonio, J. Fu, R.V. lozzo, Endorepellin, a novel inhibitor of angiogenesis derived from the C terminus of perlecan, J Biol Chem 278 (2003) 4238-49.

[48] M.A. Gubbiotti, T. Neill, R.V. lozzo, A current view of perlecan in physiology and pathology: A mosaic of functions, Matrix Biol 57-58 (2017) 285-298.

[49] E.M. Gonzalez, C.C. Reed, G. Bix, J. Fu, Y. Zhang, B. Gopalakrishnan, D.S. Greenspan, R.V. lozzo, BMP-1/Tolloid-like metalloproteases process endorepellin, the angiostatic C-terminal fragment of perlecan, J Biol Chem 280 (2005) 7080-7. 
[50] J.F. Cailhier, I. Sirois, P. Laplante, S. Lepage, M.A. Raymond, N. Brassard, A. Prat, R.V. Iozzo, A.V. Pshezhetsky, M.J. Hebert, Caspase-3 activation triggers extracellular cathepsin L release and endorepellin proteolysis, J Biol Chem 283 (2008) 27220-9.

[51] M.S. Lord, M. Jung, B. Cheng, J.M. Whitelock, Transcriptional complexity of the HSPG2 gene in the human mast cell line, HMC-1, Matrix Biol 35 (2014) 123-31.

[52] E. Forsberg, L. Kjellén, Heparan sulfate: lessons from knockout mice, J Clin Invest 108 (2001) 175-180.

[53] J. Whitelock, J. Melrose, Heparan sulfate proteoglycans in healthy and diseased systems, Wiley Interdiscip Rev Syst Biol Med 3 (2011) 739-51.

[54] A.J. Kvist, A.E. Johnson, M. Morgelin, E. Gustafsson, E. Bengtsson, K. Lindblom, A. Aszodi, R. Fassler, T. Sasaki, R. Timpl, A. Aspberg, Chondroitin sulfate perlecan enhances collagen fibril formation. Implications for perlecan chondrodysplasias, J Biol Chem 281 (2006) 3312739.

[55] Y. Yaoi, K. Hashimoto, H. Koitabashi, K. Takahara, M. Ito, I. Kato, Primary structure of the heparin-binding site of type V collagen, Biochim Biophys Acta 1035 (1990) 139-45.

[56] B. Gellersen, J.J. Brosens, Cyclic Decidualization of the Human Endometrium in Reproductive Health and Failure, Endocr Rev 35 (2014) 851-905.

[57] R.M. Bremnes, T. Dønnem, S. Al-Saad, K. Al-Shibli, S. Andersen, R. Sirera, C. Camps, I. Marinez, L.-T. Busund, The Role of Tumor Stroma in Cancer Progression and Prognosis: Emphasis on Carcinoma-Associated Fibroblasts and Non-small Cell Lung Cancer, J Thorac Oncol 6 (2011) 209-217.

[58] M.T. Levy, G.W. McCaughan, G. Marinos, M.D. Gorrell, Intrahepatic expression of the hepatic stellate cell marker fibroblast activation protein correlates with the degree of fibrosis in hepatitis C virus infection, Liver 22 (2002) 93-101.

[59] Z. Tao, F.W. Smart, J.E. Figueroa, D.L. Glancy, P. Vijayagopal, Elevated expression of proteoglycans in proliferating vascular smooth muscle cells, Atherosclerosis 135 (1997) 171179.

[60] A. Asplund, P. Stillemark-Billton, E. Larsson, E.K. Rydberg, J. Moses, L.M. Hulten, B. Fagerberg, G. Camejo, G. Bondjers, Hypoxic regulation of secreted proteoglycans in macrophages, Glycobiol 20 (2010) 33-40.

[61] A.N. Lekkerkerker, J. Aarbiou, T. van Es, R.A. Janssen, Cellular players in lung fibrosis, Curr Pharm Des 18 (2012) 4093-102.

[62] A. Andersson-Sjoland, C.G. de Alba, K. Nihlberg, C. Becerril, R. Ramirez, A. Pardo, G. Westergren-Thorsson, M. Selman, Fibrocytes are a potential source of lung fibroblasts in idiopathic pulmonary fibrosis, Int J Biochem Cell Biol 40 (2008) 2129-40.

[63] J.J. Tomasek, G. Gabbiani, B. Hinz, C. Chaponnier, R.A. Brown, Myofibroblasts and mechano-regulation of connective tissue remodelling, Nat Rev Mol Cell Biol 3 (2002) 349-63.

[64] P. Laplante, M.A. Raymond, G. Gagnon, N. Vigneault, A.M. Sasseville, Y. Langelier, M. Bernard, Y. Raymond, M.J. Hebert, Novel fibrogenic pathways are activated in response to endothelial apoptosis: implications in the pathophysiology of systemic sclerosis, J Immunol 174 (2005) 5740-9.

[65] P. Laplante, M.A. Raymond, A. Labelle, J. Abe, R.V. lozzo, M.J. Hebert, Perlecan proteolysis induces an alpha2beta1 integrin- and Src family kinase-dependent anti-apoptotic pathway in fibroblasts in the absence of focal adhesion kinase activation, J Biol Chem 281 (2006) 3038392.

[66] I. Barkefors, S. Le Jan, L. Jakobsson, E. Hejll, G. Carlson, H. Johansson, J. Jarvius, J.W. Park, N. Li Jeon, J. Kreuger, Endothelial cell migration in stable gradients of vascular endothelial growth factor $\mathrm{A}$ and fibroblast growth factor 2: effects on chemotaxis and chemokinesis, J Biol Chem 283 (2008) 13905-12.

[67] X. Guo, C.G. Elliott, Z. Li, Y. Xu, D.W. Hamilton, J. Guan, Creating 3D angiogenic growth factor gradients in fibrous constructs to guide fast angiogenesis, Biomacromolecules 13 (2012) 3262-71.

[68] A. Lundkvist, S. Lee, L. Iruela-Arispe, C. Betsholtz, H. Gerhardt, Growth factor gradients in vascular patterning, Novartis Found Symp 283 (2007) 194-201; discussion 201-6, 238-41.

[69] O. Nilsson, E.A. Parker, A. Hegde, M. Chau, K.M. Barnes, J. Baron, Gradients in bone morphogenetic protein-related gene expression across the growth plate, J Endocrinol 193 (2007) 75-84.

[70] H. Teimouri, B. Bozorgui, A.B. Kolomeisky, Development of Morphogen Gradients with Spatially Varying Degradation Rates, J Phys Chem B 120 (2016) 2745-50. 
[71] N. Hashimoto, H. Jin, T. Liu, S.W. Chensue, S.H. Phan, Bone marrow-derived progenitor cells in pulmonary fibrosis, J Clin Invest 113 (2004) 243-52.

[72] M.D. Sweeney, Y. Yu, J.A. Leary, Effects of sulfate position on heparin octasaccharide binding to CCL2 examined by tandem mass spectrometry, J Am Soc Mass Spectrom 17 (2006) 1114-9.

[73] W.G. Liang, C.G. Triandafillou, T.-Y. Huang, M.M.L. Zulueta, S. Banerjee, A.R. Dinner, S.-C. Hung, W.-J. Tang, Structural basis for oligomerization and glycosaminoglycan binding of CCL5 and CCL3, PNAS 113 (2016) 5000-5005.

[74] A. Singh, W.C. Kett, I.C. Severin, I. Agyekum, J. Duan, I.J. Amster, A.E. Proudfoot, D.R. Coombe, R.J. Woods, The Interaction of Heparin Tetrasaccharides with Chemokine CCL5 Is Modulated by Sulfation Pattern and pH, J Biol Chem 290 (2015) 15421-36.

[75] K.M. Poluri, P.R.B. Joseph, K.V. Sawant, K. Rajarathnam, Molecular Basis of Glycosaminoglycan Heparin Binding to the Chemokine CXCL1 Dimer, J Biol Chem 288 (2013) 25143-25153.

[76] P.Raj B. Joseph, Philip D. Mosier, Umesh R. Desai, K. Rajarathnam, Solution NMR characterization of chemokine CXCL8/L-8 monomer and dimer binding to glycosaminoglycans: structural plasticity mediates differential binding interactions, Biochem $\mathrm{J}$ 472 (2015) 121-133.

[77] V. Vanheule, D. Boff, A. Mortier, R. Janssens, B. Petri, E. Kolaczkowska, P. Kubes, N. Berghmans, S. Struyf, A.J. Kungl, M.M. Teixeira, F.A. Amaral, P. Proost, CXCL9-Derived Peptides Differentially Inhibit Neutrophil Migration In Vivo through Interference with Glycosaminoglycan Interactions, Front Immunol 8 (2017) 530.

[78] J.W. Murphy, Y. Cho, A. Sachpatzidis, C. Fan, M.E. Hodsdon, E. Lolis, Structural and functional basis of CXCL12 (stromal cell-derived factor-1 alpha) binding to heparin, J Biol Chem 282 (2007) 10018-27.

[79] H. Sahin, C. Trautwein, H.E. Wasmuth, Functional role of chemokines in liver disease models, Nat Rev Gastroenterol Hepatol 7 (2010) 682-90.

[80] H.K. Salem, C. Thiemermann, Mesenchymal stromal cells: current understanding and clinical status, Stem Cells 28 (2010) 585-96.

[81] S.L. Friedman, Cytokines and fibrogenesis, Semin Liver Dis 19 (1999) 129-40.

[82] R.V. lozzo, J. Pillarisetti, B. Sharma, A.D. Murdoch, K.G. Danielson, J. Uitto, A. Mauviel, Structural and functional characterization of the human perlecan gene promoter. Transcriptional activation by transforming growth factor-beta via a nuclear factor 1-binding element, J Biol Chem 272 (1997) 5219-28.

[83] V.M. Kahari, H. Larjava, J. Uitto, Differential regulation of extracellular matrix proteoglycan (PG) gene expression. Transforming growth factor-beta 1 up-regulates biglycan (PGI), and versican (large fibroblast PG) but down-regulates decorin (PGII) mRNA levels in human fibroblasts in culture, J Biol Chem 266 (1991) 10608-15.

[84] L.D. Moon, J.W. Fawcett, Reduction in CNS scar formation without concomitant increase in axon regeneration following treatment of adult rat brain with a combination of antibodies to TGFbeta1 and beta2, Eur J Neurosci 14 (2001) 1667-77.

[85] S.L. Friedman, Molecular regulation of hepatic fibrosis, an integrated cellular response to tissue injury, J Biol Chem 275 (2000) 2247-2250.

[86] Y. Ichimaru, D.I. Krimmer, J.K. Burgess, J.L. Black, B.G.G. Oliver, TGF- $\beta$ enhances deposition of perlecan from COPD airway smooth muscle, Am J Physiol Lung Cell Mol Physiol 302 (2012) L325-L333.

[87] T. Kaji, A. Yamada, S. Miyajima, C. Yamamoto, Y. Fujiwara, T.N. Wight, M.G. Kinsella, Cell density-dependent regulation of proteoglycan synthesis by transforming growth factor- $\beta 1$ in cultured bovine aortic endothelial cells, J Biol Chem 275 (2000) 1463-1470.

[88] E. Bengtsson, M. Morgelin, T. Sasaki, R. Timpl, D. Heinegard, A. Aspberg, The leucine-rich repeat protein PRELP binds perlecan and collagens and may function as a basement membrane anchor, J Biol Chem 277 (2002) 15061-8.

[89] M. Costell, E. Gustafsson, A. Aszodi, M. Morgelin, W. Bloch, E. Hunziker, K. Addicks, R. Timpl, R. Fassler, Perlecan maintains the integrity of cartilage and some basement membranes, J Cell Biol 147 (1999) 1109-22.

[90] R.V. lozzo, Basement membrane proteoglycans: from cellar to ceiling, Nat Rev Mol Cell Biol 6 (2005) 646-56.

[91] D.T. Behrens, D. Villone, M. Koch, G. Brunner, L. Sorokin, H. Robenek, L. BrucknerTuderman, P. Bruckner, U. Hansen, The epidermal basement membrane is a composite of 
separate laminin- or collagen IV-containing networks connected by aggregated perlecan, but not by nidogens, J Biol Chem 287 (2012) 18700-9.

[92] R. Timpl, Macromolecular organization of basement membranes, Curr Opin Cell Biol 8 (1996) 618-24.

[93] I.E. Fernandez, O. Eickelberg, New cellular and molecular mechanisms of lung injury and fibrosis in idiopathic pulmonary fibrosis, Lancet 380 (2012) 680-8.

[94] J.K. Burgess, T. Mauad, G. Tjin, J.C. Karlsson, G. Westergren-Thorsson, The extracellular matrix - the under-recognized element in lung disease?, J Pathol 240 (2016) 397-409.

[95] M. Chilosi, V. Poletti, A. Rossi, The pathogenesis of COPD and IPF: Distinct horns of the same devil?, Respir Res 13 (2012) 3-3.

[96] Y. Yang, S.Y. Zhang, M. Sich, A. Beziau, L.P. van den Heuvel, M.C. Gubler, Glomerular extracellular matrix and growth factors in diffuse mesangial sclerosis, Pediatr Nephrol 16 (2001) 429-38.

[97] G. Thomas, A. Clayton, J. Thomas, M. Davies, R. Steadman, Structural and functional changes in heparan sulfate proteoglycan expression associated with the myofibroblastic phenotype, Am J Pathol 162 (2003) 977-89.

[98] C. Kotaru, K.J. Schoonover, J.B. Trudeau, M.L. Huynh, X. Zhou, H. Hu, S.E. Wenzel, Regional fibroblast heterogeneity in the lung: implications for remodeling, Am J Respir Crit Care Med 173 (2006) 1208-15.

[99] O. Hallgren, K. Nihlberg, M. Dahlback, L. Bjermer, L.T. Eriksson, J.S. Erjefalt, C.G. Lofdahl, G. Westergren-Thorsson, Altered fibroblast proteoglycan production in COPD, Respir Res 11 (2010) 55.

[100] G. Westergren-Thorsson, M. Bagher, A. Andersson-Sjoland, L. Thiman, C.G. Lofdahl, O. Hallgren, L. Bjermer, A.K. Larsson-Callerfelt, VEGF synthesis is induced by prostacyclin and TGF-beta in distal lung fibroblasts from COPD patients and control subjects: Implications for pulmonary vascular remodelling, Respirology (2017).

[101] J. Malmstrom, K. Larsen, L. Hansson, C.G. Lofdahl, O. Norregard-Jensen, G. Marko-Varga, G. Westergren-Thorsson, Proteoglycan and proteome profiling of central human pulmonary fibrotic tissue utilizing miniaturized sample preparation: a feasibility study, Proteomics 2 (2002) 394-404.

[102] D.I. Krimmer, J.K. Burgess, T.K. Wooi, J.L. Black, B.G. Oliver, Matrix proteins from smokeexposed fibroblasts are pro-proliferative, Am J Respir Cell Mol Biol 46 (2012) 34-9.

[103] N. Venkatesan, T. Ebihara, P.J. Roughley, M.S. Ludwig, Alterations in large and small proteoglycans in bleomycin-induced pulmonary fibrosis in rats, Am J Respir Crit Care Med 161 (2000) 2066-73.

[104] N. Venkatesan, P.J. Roughley, M.S. Ludwig, Proteoglycan expression in bleomycin lung fibroblasts: role of transforming growth factor-beta(1) and interferon-gamma, Am J Physiol Lung Cell Mol Physiol 283 (2002) L806-14.

[105] K. Nihlberg, A. Andersson-Sjoland, E. Tufvesson, J.S. Erjefalt, L. Bjermer, G. WestergrenThorsson, Altered matrix production in the distal airways of individuals with asthma, Thorax 65 (2010) 670-6.

[106] Q. Ge, L. Chen, J. Jaffar, W.S. Argraves, W.O. Twal, P. Hansbro, J.L. Black, J.K. Burgess, B. Oliver, Fibulin1C peptide induces cell attachment and extracellular matrix deposition in lung fibroblasts, Sci Rep 5 (2015) 9496.

[107] G. Westergren-Thorsson, U. Hedstrom, A. Nybom, E. Tykesson, E. Ahrman, M. Hornfelt, M. Maccarana, T.H. van Kuppevelt, G. Dellgren, M. Wildt, X.H. Zhou, L. Eriksson, L. Bjermer, O. Hallgren, Increased deposition of glycosaminoglycans and altered structure of heparan sulfate in idiopathic pulmonary fibrosis, Int J Biochem Cell Biol 83 (2017) 27-38.

[108] M. Zeisberg, K. Kramer, N. Sindhi, P. Sarkar, M. Upton, R. Kalluri, De-differentiation of primary human hepatocytes depends on the composition of specialized liver basement membrane, Mol Cell Biochem 283 (2006) 181-189.

[109] A. Martinez-Hernandez, P.S. Amenta, The hepatic extracellular matrix. I. Components and distribution in normal liver, Virchows Arch A Pathol Anat Histopathol 423 (1993) 1-11.

[110] K.M. Mak, L.L. Chen, T.F. Lee, Codistribution of collagen type IV and laminin in liver fibrosis of elderly cadavers: Immunohistochemical marker of perisinusoidal basement membrane formation, Anat Rec 296 (2013) 953-964.

[111] M. Gallai, I. Kovalszky, T. Knittel, K. Neubauer, T. Armbrust, G. Ramadori, Expression of extracellular matrix proteoglycans perlecan and decorin in carbon-tetrachloride-injured rat liver and in isolated liver cells, Am J Pathol 148 (1996) 1463-71. 
[112] M. Rojkind, P. Ponce-Noyola, The extracellular matrix of the liver, Coll Relat Res 2 (1982) 151-75.

[113] J.Y. Chen, E.R. Feeney, R.T. Chung, HCV and HIV co-infection: Mechanisms and management, Nat Rev Gastroenterol Hepatol 11 (2014) 362-371.

[114] A. Martinez-Hernandez, J. Martinez, The role of capillarization in hepatic failure: studies in carbon tetrachloride-induced cirrhosis, Hepatology 14 (1991) 864-74.

[115] N.-T.A. Nguyen, D. Roberge, C.R. Freeman, C. Wong, J. Hines, R.E. Turcotte, Skin elasticity as a measure of radiation fibrosis: Is it reproducible and does it correlate with patient and physician-reported measures?, Technol Cancer Res Treat 13 (2014) 469-476.

[116] O. Musso, M. Rehn, J. Saarela, N. Theret, J. Lietard, Hintikka, D. Lotrian, J.P. Campion, T. Pihlajaniemi, B. Clement, Collagen XVIII is localized in sinusoids and basement membrane zones and expressed by hepatocytes and activated stellate cells in fibrotic human liver, Hepatology 28 (1998) 98-107.

[117] D. Cassiman, L. Libbrecht, V. Desmet, C. Denef, T. Roskams, Hepatic stellate cell/myofibroblast subpopulations in fibrotic human and rat livers, J Hepatol 36 (2002) 200-9.

[118] A. Mitra, J.I. Luna, A.I. Marusina, A. Merleev, S. Kundu-Raychaudhuri, D. Fiorentino, S.P. Raychaudhuri, E. Maverakis, Dual mTOR inhibition is required to prevent TGF-beta-mediated fibrosis: Implications for scleroderma, J Invest Dermatol 135 (2015) 2873-2876.

[119] A. Leask, Signaling in fibrosis: targeting the TGF beta, endothelin-1 and CCN2 axis in scleroderma, Front Biosci 1 (2009) 115-22.

[120] A. Leask, D.J. Abraham, TGF-beta signaling and the fibrotic response, FASEB J 18 (2004) 816-27.

[121] A. Leask, C.P. Denton, D.J. Abraham, Insights into the molecular mechanism of chronic fibrosis: the role of connective tissue growth factor in scleroderma, J Invest Dermatol 122 (2004) 1-6.

[122] M. Pinzani, F. Marra, V. Carloni, Signal transduction in hepatic stellate cells, Liver 18 (1998) $2-13$.

[123] F. Marra, R.G. Romanelli, C. Giannini, P. Failli, S. Pastacaldi, M.C. Arrighi, M. Pinzani, G. Laffi, P. Montalto, P. Gentilini, Monocyte chemotactic protein-1 as a chemoattractant for human hepatic stellate cells, Hepatology 29 (1999) 140-8.

[124] J.W.A.M. Celie, N.W.P. Rutjes, E.D. Keuning, R. Soininen, R. Heljasvaara, T. Pihlajaniemi, A.M. Dräger, S. Zweegman, F.L. Kessler, R.H.J. Beelen, S. Florquin, J. Aten, J. van den Born, Subendothelial heparan sulfate proteoglycans become major L-selectin and monocyte chemoattractant protein-1 ligands upon renal ischemia/reperfusion, Am J Pathol 170 (2007) 1865-1878.

[125] A.M. Gressner, N. Krull, M.G. Bachem, Regulation of proteoglycan expression in fibrotic liver and cultured fat-storing cells, Pathol Res Pract 190 (1994) 864-882.

[126] P. Tátrai, K. Egedi, Á. Somorácz, T.H. van Kuppevelt, G. ten Dam, M. Lyon, J. Deakin, Z. Schaff, I. Kovalszky, Quantitative and qualitative alterations of heparan sulfate in fibrogenic liver diseases and hepatocellular cancer, J Histochem Cytochem 58 (2010) 429-441.

[127] D. Edgar, R. Timpl, H. Thoenen, The heparin-binding domain of laminin is responsible for its effects on neurite outgrowth and neuronal survival, EMBO J 3 (1984) 1463-8.

[128] K.M. Mak, C.Y. Png, D.J. Lee, Type V collagen in health, disease, and fibrosis, Anat Rec 299 (2016) 613-29.

[129] M.J. Arthur, Collagenases and liver fibrosis, J Hepatol 22 (1995) 43-8.

[130] J.M. Whitelock, A.D. Murdoch, R.V. Iozzo, P.A. Underwood, The degradation of human endothelial cell-derived perlecan and release of bound basic fibroblast growth factor by stromelysin, collagenase, plasmin, and heparanases, J Biol Chem 271 (1996) 10079-86.

[131] G. Westergren-Thorsson, K. Larsen, K. Nihlberg, A. Andersson-Sjoland, O. Hallgren, G. Marko-Varga, L. Bjermer, Pathological airway remodelling in inflammation, Clin Respir J 4 Suppl 1 (2010) 1-8.

[132] N. Theret, K. Lehti, O. Musso, B. Clement, MMP2 activation by collagen I and concanavalin A in cultured human hepatic stellate cells, Hepatology 30 (1999) 462-8.

[133] J.P. Iredale, A. Thompson, N.C. Henderson, Extracellular matrix degradation in liver fibrosis: Biochemistry and regulation, Biochim Biophys Acta 1832 (2013) 876-83.

[134] S. Ozaki, Y. Sato, M. Yasoshima, K. Harada, Y. Nakanuma, Diffuse expression of heparan sulfate proteoglycan and connective tissue growth factor in fibrous septa with many mast cells relate to unresolving hepatic fibrosis of congenital hepatic fibrosis, Liver Int 25 (2005) 817828. 
[135] M. Dos Santos, A. Michopoulou, V. André-Frei, S. Boulesteix, C. Guicher, G. Dayan, J. Whitelock, O. Damour, P. Rousselle, Perlecan expression influences the keratin 15-positive cell population fate in the epidermis of aging skin, Aging 8 (2016) 751-768.

[136] M. Zeisberg, Y. Maeshima, B. Mosterman, R. Kalluri, Renal fibrosis. Extracellular matrix microenvironment regulates migratory behavior of activated tubular epithelial cells, $\mathrm{Am} \mathrm{J}$ Pathol 160 (2002) 2001-8.

[137] J.S. Duffield, Cellular and molecular mechanisms in kidney fibrosis, J Clin Invest 124 (2014) 2299-2306.

[138] L. Schaefer, R.M. Schaefer, Proteoglycans: from structural compounds to signaling molecules, Cell Tissue Res 339 (2010) 237-46.

[139] L.J. Rosenzweig, Y.S. Kanwar, Removal of sulfated (heparan sulfate) or nonsulfated (hyaluronic acid) glycosaminoglycans results in increased permeability of the glomerular basement membrane to 125I-bovine serum albumin, Lab Invest 47 (1982) 177-84.

[140] K. Ebefors, A. Granqvist, M. Ingelsten, J. Molne, B. Haraldsson, J. Nystrom, Role of glomerular proteoglycans in IgA nephropathy, PLoS One 6 (2011) e18575.

[141] K. Conde-Knape, Heparan sulfate proteoglycans in experimental models of diabetes: a role for perlecan in diabetes complications, Diabetes Metab Res Rev 17 (2001) 412-21.

[142] M. Ceol, G. Gambaro, U. Sauer, B. Baggio, F. Anglani, M. Forino, S. Facchin, L. Bordin, C. Weigert, A. Nerlich, E.D. Schleicher, Glycosaminoglycan therapy prevents TGF-beta1 overexpression and pathologic changes in renal tissue of long-term diabetic rats, J Am Soc Nephrol 11 (2000) 2324-36.

[143] S. Yung, M.K. Chau, Q. Zhang, C.Z. Zhang, T.M. Chan, Sulodexide decreases albuminuria and regulates matrix protein accumulation in C57BL/6 mice with streptozotocin-induced type I diabetic nephropathy, PLoS One 8 (2013) e54501.

[144] H. Rienstra, K. Katta, J.W. Celie, H. van Goor, G. Navis, J. van den Born, J.L. Hillebrands, Differential expression of proteoglycans in tissue remodeling and lymphangiogenesis after experimental renal transplantation in rats, PLoS One 5 (2010) e9095.

[145] M.V. Sofroniew, Molecular dissection of reactive astrogliosis and glial scar formation, Trends Neurosci 32 (2009) 638-47.

[146] A. Rolls, R. Shechter, M. Schwartz, The bright side of the glial scar in CNS repair, Nat Rev Neurosci 10 (2009) 235-241.

[147] C.S. Barros, S.J. Franco, U. Müller, Extracellular Matrix: Functions in the Nervous System, Cold Spring Harb Perspect Biol 3 (2011) a005108.

[148] N. Haubst, E. Georges-Labouesse, A. De Arcangelis, U. Mayer, M. Gotz, Basement membrane attachment is dispensable for radial glial cell fate and for proliferation, but affects positioning of neuronal subtypes, Development 133 (2006) 3245-54.

[149] A. Giros, J. Morante, C. Gil-Sanz, A. Fairen, M. Costell, Perlecan controls neurogenesis in the developing telencephalon, BMC Dev Biol 7 (2007) 29.

[150] F. Matsui, A. Oohira, Proteoglycans and injury of the central nervous system, Congenit Anom 44 (2004) 181-8.

[151] D.B.L. Teh, A. Prasad, W. Jiang, M.Z. Ariffin, S. Khanna, A. Belorkar, L. Wong, X. Liu, A.H. All, Transcriptome Analysis Reveals Neuroprotective aspects of Human Reactive Astrocytes induced by Interleukin 1beta, Sci Rep 7 (2017) 13988.

[152] T.M. Hering, J.A. Beller, C.M. Calulot, A. Centers, D.M. Snow, Proteoglycans of reactive rat cortical astrocyte cultures: abundance of $\mathrm{N}$-unsubstituted glucosamine-enriched heparan sulfate, Matrix Biol 41 (2015) 8-18.

[153] A.J. Al-Ahmad, B. Lee, M. Saini, G.J. Bix, Perlecan domain V modulates astrogliosis in vitro and after focal cerebral ischemia through multiple receptors and increased nerve growth factor release, Glia 59 (2011) 1822-40.

[154] J.A. Beller, D.M. Snow, Proteoglycans: road signs for neurite outgrowth, Neural Regen Res 9 (2014) 343-55.

[155] M.K.E. Schafer, I. Tegeder, NG2/CSPG4 and progranulin in the posttraumatic glial scar, Matrix Biol (2017).

[156] L. Menzel, L. Kleber, C. Friedrich, R. Hummel, L. Dangel, J. Winter, K. Schmitz, I. Tegeder, M.K. Schafer, Progranulin protects against exaggerated axonal injury and astrogliosis following traumatic brain injury, Glia 65 (2017) 278-292.

[157] E.M. Gonzalez, M. Mongiat, S.J. Slater, R. Baffa, R.V. lozzo, A novel interaction between perlecan protein core and progranulin: potential effects on tumor growth, J Biol Chem 278 (2003) 38113-6. 
[158] F. Tang, M.S. Lord, W.B. Stallcup, J.M. Whitelock, Cell surface chondroitin sulfate proteoglycan 4 (CSPG4) binds to the basement membrane heparan sulfate proteoglycan, perlecan, and is involved in cell adhesion, J Biochem accepted 9 November 2017 (2017).

[159] B. Lee, D. Clarke, A. Al Ahmad, M. Kahle, C. Parham, L. Auckland, C. Shaw, M. Fidanboylu, A.W. Orr, O. Ogunshola, A. Fertala, S.A. Thomas, G.J. Bix, Perlecan domain V is neuroprotective and proangiogenic following ischemic stroke in rodents, J Clin Invest 121 (2011) 3005-23.

[160] L.R. Tannock, V.L. King, Proteoglycan mediated lipoprotein retention: a mechanism of diabetic atherosclerosis, Rev Endocr Metab Disord 9 (2008) 289-300.

[161] R. Ross, Atherosclerosis--an inflammatory disease, N Engl J Med 340 (1999) 115-26.

[162] P.K. Tran, H.E. Agardh, K. Tran-Lundmark, J. Ekstrand, J. Roy, B. Henderson, A. Gabrielsen, G.K. Hansson, J. Swedenborg, G. Paulsson-Berne, U. Hedin, Reduced perlecan expression and accumulation in human carotid atherosclerotic lesions, Atherosclerosis 190 (2007) 26470.

[163] K. Hayashi, J.A. Madri, P.D. Yurchenco, Endothelial cells interact with the core protein of basement membrane perlecan through beta 1 and beta 3 integrins: an adhesion modulated by glycosaminoglycan, J Cell Biol 119 (1992) 945-59.

[164] J. Thyberg, K. Blomgren, J. Roy, P.K. Tran, U. Hedin, Phenotypic modulation of smooth muscle cells after arterial injury is associated with changes in the distribution of laminin and fibronectin, J Histochem Cytochem 45 (1997) 837-46.

[165] I.P. Hayward, K.R. Bridle, G.R. Campbell, P.A. Underwood, J.H. Campbell, Effect of extracellular matrix proteins on vascular smooth muscle cell phenotype, Cell Biol Int 19 (1995) 727-34.

[166] S.P. Evanko, E.W. Raines, R. Ross, L.I. Gold, T.N. Wight, Proteoglycan distribution in lesions of atherosclerosis depends on lesion severity, structural characteristics, and the proximity of platelet-derived growth factor and transforming growth factor-beta, Am J Pathol 152 (1998) 533-546.

[167] U. Hedin, J. Roy, P.K. Tran, K. Lundmark, A. Rahman, Control of smooth muscle cell proliferation--the role of the basement membrane, Thromb Haemost 82 Suppl 1 (1999) 23-6.

[168] M.S. Lord, B. Cheng, S.J. McCarthy, M. Jung, J.M. Whitelock, The modulation of platelet adhesion and activation by chitosan through plasma and extracellular matrix proteins, Biomaterials 32 (2011) 6655-62.

[169] E. Hammond, A. Khurana, V. Shridhar, K. Dredge, The role of heparanase and sulfatases in the modification of heparan sulfate proteoglycans within the tumor microenvironment and opportunities for novel cancer therapeutics, Front Oncol 4 (2014) 195.

[170] M.G. Kinsella, P.K. Tran, M.C. Weiser-Evans, M. Reidy, R.A. Majack, T.N. Wight, Changes in perlecan expression during vascular injury: role in the inhibition of smooth muscle cell proliferation in the late lesion, Arterioscler Thromb Vasc Biol 23 (2003) 608-14.

[171] Y. Sato, R. Hamanaka, J. Ono, M. Kuwano, D.B. Rifkin, R. Takaki, The stimulatory effect of PDGF on vascular smooth muscle cell migration is mediated by the induction of endogenous basic FGF, Biochem Biophys Res Commun 174 (1991) 1260-6.

[172] K. Tran-Lundmark, P.K. Tran, G. Paulsson-Berne, V. Friden, R. Soininen, K. Tryggvason, T.N. Wight, M.G. Kinsella, J. Boren, U. Hedin, Heparan sulfate in perlecan promotes mouse atherosclerosis: roles in lipid permeability, lipid retention, and smooth muscle cell proliferation, Circ Res 103 (2008) 43-52.

[173] M.C. Weiser, N.A. Grieshaber, P.E. Schwartz, R.A. Majack, Perlecan regulates Oct-1 gene expression in vascular smooth muscle cells, Mol Biol Cell 8 (1997) 999-1011.

[174] L. Paka, I.J. Goldberg, J.C. Obunike, S.Y. Choi, U. Saxena, I.D. Goldberg, S. Pillarisetti, Perlecan mediates the antiproliferative effect of apolipoprotein $E$ on smooth muscle cells. An underlying mechanism for the modulation of smooth muscle cell growth?, J Biol Chem 274 (1999) 36403-8.

[175] C. Yamamoto, T. Wakata, Y. Fujiwara, T. Kaji, Induction of synthesis of a large heparan sulfate proteoglycan, perlecan, by thrombin in cultured human coronary smooth muscle cells, Biochim Biophys Acta 1722 (2005) 92-102.

[176] N. Fujii, T. Kaji, T. Akai, F. Koizumi, Thrombin Reduces Large Heparan Sulfate Proteoglycan Molecules in Cultured Vascular Endothelial Cell Layers through Inhibition of Core Protein Synthesis, Thromb Res 88 (1997) 299-307.

[177] B.H. Rauch, E. Millette, R.D. Kenagy, G. Daum, A.W. Clowes, Thrombin- and factor Xainduced DNA synthesis is mediated by transactivation of fibroblast growth factor receptor- 1 in human vascular smooth muscle cells, Circ Res 94 (2004) 340-5. 
[178] R.T. Lee, C. Yamamoto, Y. Feng, S. Potter-Perigo, W.H. Briggs, K.T. Landschulz, T.G. Turi, J.F. Thompson, P. Libby, T.N. Wight, Mechanical strain induces specific changes in the synthesis and organization of proteoglycans by vascular smooth muscle cells, J Biol Chem 276 (2001) 13847-51.

[179] R. Shimizu-Hirota, H. Sasamura, M. Mifune, H. Nakaya, M. Kuroda, M. Hayashi, T. Saruta, Regulation of vascular proteoglycan synthesis by angiotensin II type 1 and type 2 receptors, J Am Soc Nephrol 12 (2001) 2609-15.

[180] S. Ohkawara, C. Yamamoto, Y. Fujiwara, M. Sakamoto, T. Kaji, Cadmium induces the production of high molecular weight heparan sulfate proteoglycan molecules in cultured vascular endothelial cells, Environ Toxicol Pharmacol 3 (1997) 187-94.

[181] V.V. Kunjathoor, D.S. Chiu, K.D. O'Brien, R.C. LeBoeuf, Accumulation of biglycan and perlecan, but not versican, in lesions of murine models of atherosclerosis, Arterioscler Thromb Vasc Biol 22 (2002) 462-8.

[182] M.D. Rees, J.M. Whitelock, E. Malle, C.Y. Chuang, R.V. lozzo, A. Nilasaroya, M.J. Davies, Myeloperoxidase-derived oxidants selectively disrupt the protein core of the heparan sulfate proteoglycan perlecan, Matrix Biol 29 (2010) 63-73.

[183] C.Y. Chuang, G. Degendorfer, A. Hammer, J.M. Whitelock, E. Malle, M.J. Davies, Oxidation modifies the structure and function of the extracellular matrix generated by human coronary artery endothelial cells, Biochem J 459 (2014) 313-22.

[184] E.C. Kennett, M.D. Rees, E. Malle, A. Hammer, J.M. Whitelock, M.J. Davies, Peroxynitrite modifies the structure and function of the extracellular matrix proteoglycan perlecan by reaction with both the protein core and the heparan sulfate chains, Free Radic Biol Med 49 (2010) 282-93.

[185] M.A. Raymond, A. Desormeaux, P. Laplante, N. Vigneault, J.G. Filep, K. Landry, A.V. Pshezhetsky, M.J. Hebert, Apoptosis of endothelial cells triggers a caspase-dependent antiapoptotic paracrine loop active on VSMC, FASEB J 18 (2004) 705-7.

[186] A. Goyal, N. Pal, M. Concannon, M. Paul, M. Doran, C. Poluzzi, K. Sekiguchi, J.M. Whitelock, T. Neill, R.V. lozzo, Endorepellin, the angiostatic module of perlecan, interacts with both the alpha2beta1 integrin and vascular endothelial growth factor receptor 2 (VEGFR2): a dual receptor antagonism, J Biol Chem 286 (2011) 25947-62.

[187] G. Bix, R. Castello, M. Burrows, J.J. Zoeller, M. Weech, R.A. Iozzo, C. Cardi, M.L. Thakur, C.A. Barker, K. Camphausen, R.V. Iozzo, Endorepellin in vivo: targeting the tumor vasculature and retarding cancer growth and metabolism, J Natl Cancer Inst 98 (2006) 163446.

[188] B.P. Woodall, A. Nystrom, R.A. lozzo, J.A. Eble, S. Niland, T. Krieg, B. Eckes, A. Pozzi, R.V. lozzo, Integrin alpha2beta1 is the required receptor for endorepellin angiostatic activity, J Biol Chem 283 (2008) 2335-43.

[189] C.D. Willis, C. Poluzzi, M. Mongiat, R.V. lozzo, Endorepellin laminin-like globular 1/2 domains bind Ig3-5 of vascular endothelial growth factor (VEGF) receptor 2 and block pro-angiogenic signaling by VEGFA in endothelial cells, FEBS J 280 (2013) 2271-84.

[190] N. Koyama, M.G. Kinsella, T.N. Wight, U. Hedin, A.W. Clowes, Heparan sulfate proteoglycans mediate a potent inhibitory signal for migration of vascular smooth muscle cells, Circ Res 83 (1998) 305-13.

[191] T. Tang, P.G. Wilson, J.C. Thompson, C. Nelson, M.H. Yoder, L.R. Tannock, Prevention of TGFbeta induction attenuates angll-stimulated vascular biglycan and atherosclerosis in Ldlr-/mice, J Lipid Res 54 (2013) 2255-64.

[192] S.O. Marx, H. Totary-Jain, A.R. Marks, Vascular smooth muscle cell proliferation in restenosis, Circulation 4 (2011) 104-11.

[193] E.W. Raines, The extracellular matrix can regulate vascular cell migration, proliferation, and survival: relationships to vascular disease, Int J Exp Pathol 81 (2000) 173-182.

[194] S. Knox, C. Merry, S. Stringer, J. Melrose, J. Whitelock, Not all perlecans are created equal: interactions with fibroblast growth factor (FGF) 2 and FGF receptors, J Biol Chem 277 (2002) 14657-65.

[195] P.K. Tran, K. Tran-Lundmark, R. Soininen, K. Tryggvason, J. Thyberg, U. Hedin, Increased intimal hyperplasia and smooth muscle cell proliferation in transgenic mice with heparan sulfate-deficient perlecan, Circ Res 94 (2004) 550-8.

[196] J.A. Bingley, I.P. Hayward, J.H. Campbell, G.R. Campbell, Arterial heparan sulfate proteoglycans inhibit vascular smooth muscle cell proliferation and phenotype change in vitro and neointimal formation in vivo, J Vasc Surg 28 (1998) 308-18. 
[197] V. Masola, M. Onisto, G. Zaza, A. Lupo, G. Gambaro, A new mechanism of action of sulodexide in diabetic nephropathy: inhibits heparanase-1 and prevents FGF-2-induced renal epithelial-mesenchymal transition, J Transl Med 10 (2012) 213.

[198] N. Nagy, A. Melchior-Becker, J.W. Fischer, Long-term treatment with the AT1-receptor antagonist telmisartan inhibits biglycan accumulation in murine atherosclerosis, Basic Res Cardiol 105 (2010) 29-38.

[199] A. Hajari Case, P. Johnson, Clinical use of nintedanib in patients with idiopathic pulmonary fibrosis, MJ Open Respir Res 4 (2017).

[200] F. Hilberg, G.J. Roth, M. Krssak, S. Kautschitsch, W. Sommergruber, U. Tontsch-Grunt, P. Garin-Chesa, G. Bader, A. Zoephel, J. Quant, A. Heckel, W.J. Rettig, BIBF 1120: triple angiokinase inhibitor with sustained receptor blockade and good antitumor efficacy, Cancer Res 68 (2008) 4774-82.

[201] L. Wollin, I. Maillet, V. Quesniaux, A. Holweg, B. Ryffel, Antifibrotic and Anti-inflammatory Activity of the Tyrosine Kinase Inhibitor Nintedanib in Experimental Models of Lung Fibrosis, $J$ Pharmacol Exp Ther 349 (2014) 209-220.

[202] L. Wollin, E. Wex, A. Pautsch, G. Schnapp, K.E. Hostettler, S. Stowasser, M. Kolb, Mode of action of nintedanib in the treatment of idiopathic pulmonary fibrosis, Eur Resp J 45 (2015) 1434-1445.

[203] Y. Wang, J. Gao, D. Zhang, J. Zhang, J. Ma, H. Jiang, New insights into the antifibrotic effects of sorafenib on hepatic stellate cells and liver fibrosis, J Hepatol 53 (2010) 132-44.

[204] E. Borkham-Kamphorst, D. Stoll, A.M. Gressner, R. Weiskirchen, Antisense strategy against PDGF B-chain proves effective in preventing experimental liver fibrogenesis, Biochem Biophys Res Commun 321 (2004) 413-23.

[205] S. Ogawa, T. Ochi, H. Shimada, K. Inagaki, I. Fujita, A. Nii, M.A. Moffat, M. Katragadda, B.N. Violand, R.H. Arch, J.L. Masferrer, Anti-PDGF-B monoclonal antibody reduces liver fibrosis development, Hepatol Res 40 (2010) 1128-41.

[206] S. Nakayama, H. Mukae, N. Sakamoto, T. Kakugawa, S. Yoshioka, H. Soda, H. Oku, Y. Urata, T. Kondo, H. Kubota, K. Nagata, S. Kohno, Pirfenidone inhibits the expression of HSP47 in TGF-beta1-stimulated human lung fibroblasts, Life Sci 82 (2008) 210-7.

[207] K. Hisatomi, H. Mukae, N. Sakamoto, Y. Ishimatsu, T. Kakugawa, S. Hara, H. Fujita, S. Nakamichi, H. Oku, Y. Urata, H. Kubota, K. Nagata, S. Kohno, Pirfenidone inhibits TGF- $\beta 1$ induced over-expression of collagen type I and heat shock protein 47 in A549 cells, BMC Pulm Med 12 (2012) 24-24.

[208] A. Di Sario, E. Bendia, G. Svegliati Baroni, F. Ridolfi, A. Casini, E. Ceni, S. Saccomanno, M. Marzioni, L. Trozzi, P. Sterpetti, S. Taffetani, A. Benedetti, Effect of pirfenidone on rat hepatic stellate cell proliferation and collagen production, J Hepatol 37 (2002) 584-91.

[209] E. Conte, E. Gili, E. Fagone, M. Fruciano, M. Iemmolo, C. Vancheri, Effect of pirfenidone on proliferation, TGF-beta-induced myofibroblast differentiation and fibrogenic activity of primary human lung fibroblasts, Eur J Pharm Sci 58 (2014) 13-9.

[210] M.S. Bittencourt, R.J. Cerci, Statin effects on atherosclerotic plaques: regression or healing?, BMC Medicine 13 (2015) 260.

[211] A. Marzoll, A. Melchior-Becker, F. Cipollone, J.W. Fischer, Small leucine-rich proteoglycans in atherosclerotic lesions: novel targets of chronic statin treatment?, J Cell Mol Med 15 (2011) 232-43.

[212] A. Segev, N. Nili, A.B. Osherov, B. Qiang, A.J. Wong, S. Pillarisetti, B.H. Strauss, A perlecaninducing compound significantly inhibits smooth muscle cell function and in-stent intimal hyperplasia: novel insights into the diverse biological effects of perlecan, Eurolntervention 6 (2010) 134-40. 